\title{
Principles and Practice of Investigating Buried Adobe Features with Ground-Penetrating Radar
}

\author{
Scott Byram ${ }^{1, *}$ and Jun Ueno Sunseri ${ }^{2}$ (I) \\ 1 Research Affiliate Archaeological Research Facility, University of California, Berkeley, CA 94720, USA \\ 2 Department of Anthropology, University of California, Berkeley, CA 94720, USA; jsunseri@berkeley.edu \\ * Correspondence: scottbyram@featuresurvey.com
}

check for updates

Citation: Byram, S.; Sunseri, J.U. Principles and Practice of Investigating Buried Adobe Features with Ground-Penetrating Radar. Remote Sens. 2021, 13, 4980. https:// doi.org/10.3390/rs13244980

Academic Editors: Lara De Giorgi and Giovanni Leucci

Received: 27 October 2021

Accepted: 26 November 2021

Published: 8 December 2021

Publisher's Note: MDPI stays neutral with regard to jurisdictional claims in published maps and institutional affiliations.

Copyright: (c) 2021 by the authors. Licensee MDPI, Basel, Switzerland. This article is an open access article distributed under the terms and conditions of the Creative Commons Attribution (CC BY) license (https:// creativecommons.org/licenses/by/ $4.0 /)$.

\begin{abstract}
Because so many ancestral populations, at various times, have lived within the constraints of earthen architectural technology, it has significant representation in building traditions across large temporal and geographic expanses. Adobe, known also as dagga, ferey, cob, and by other names, is a variant in which clays and other sediments are combined with organic materials and formulated into discrete construction components, often in communities of practice for which adobe recipes, preparation, and application are integral to daily intersections of home and community. For archaeologists, community partners, and interested publics who wish to learn more about it, a large portion of this architectural culture is no longer visible above the surface but is accessible through archaeology. Yet low impact sampling, such as probing and test excavation, rarely reveals adobe features. Ground-penetrating radar (GPR) allows a tantalizing and non-invasive perspective on subsurface adobe features; increasingly there is a buried structural landscape emerging at sites where adobe architecture prevailed. The case studies presented here from 18th and 19th century sites in central and southern California serve as a guide for further survey.
\end{abstract}

Keywords: adobe architecture; ground-penetrating radar; geophysics; historical archaeology; California missions; interiography

\section{Introduction}

Earthen architecture has significant representation in building traditions across large temporal and geographic expanses. Adobe, known also as dagga, ferey, cob, and by other names, is a variant in which soil and other materials are formulated into discrete construction components, often in communities of practice for which adobe recipes, preparation, and application are integral to daily intersections of home and community. Its properties of insulation are well known. Comprised of bricks, incorporating clay mixed with organic material and sun-dried, often with stone foundations and paint or plaster, adobe can be used for large structures in areas where wood is scarce, provided that adequate roofing is feasible.

For interested archaeologists, a large portion of this architectural culture is no longer visible above the surface, except in tels and other mounded spaces resulting from long sequences of adobe collapse and replacement. In general, adobe ruins "melt" into surrounding soils soon after abandonment. Adobe can be a relatively stable structural material even in areas of seasonal rainfall, provided that the walls are protected from excessive moisture and maintained by a wide range of specific cultural processes of replastering and roof replacement. Stone foundations are also key in that they elevate the adobe bricks above ground water.

When roofed areas collapse and exterior surfacing erodes, the durability of this remarkable material quickly deteriorates. The well-known adobe "melting" process is frequently documented at archaeological sites in places such as California, where weathered adobe becomes a dense clay layer spreading well beyond its original linear wall footprint. The 
rubble foundations of adobe walls often remain beneath the adobe melt, and these are sometimes identified through archaeological trenching or incidental excavation for utilities, construction, etc. Less frequently, they are identified through shovel probing and augering. In some cases, only the stone foundations are evident because the melt has become incorporated into shallow soils through organic activity, plowing or landscaping.

Traditional archaeological field techniques for identifying adobe wall foundations have many limitations. Archaeological test excavation for the purpose of identifying adobe wall foundations may be inadequate due to the volume of excavation needed to identify these linear features, especially where historic records are absent or imprecise about building locations. In addition, similarities in matrices or incorporation of adobe materials into surrounding soils can make visual identification of adobe margins difficult. Manual resistance probing with a metal rod in soft soil has been shown to be effective [1], though has the potential to be destructive of artifacts, such as pots, as well as bone and other materials. It also suffers from superimposition of resistant materials or stone over underlying materials of interest. Resistance probing has not been demonstrated to be useful beyond delineation of partially exposed or archivally documented structures. Trenching and blading to reveal wall foundations [2], though informative, may be highly destructive of site deposits. Therefore, ground-penetrating radar survey that reveals the presence, extent, and configuration of adobe wall foundations without disturbing features has high potential.

Ground-penetrating radar has been used at several adobe sites [3-6], and in recent years the technique has proven to be highly effective for feature identification and characterization in sites across much of California. In particular, the technique allows the stone foundations of adobe walls to be mapped, and the size and position of stone constituents to be explored. In some cases, adobe bricks are also identified in GPR surveys. In some instances, the dielectric properties of adobe bricks and/or adobe melt capping foundations appears to cloak the presence of deeper stone features, but even in these settings there may be useful data generated through GPR survey. Previous work [7] has shown that an interiographic approach to GPR interpretation may provide more nuanced understanding of subsurface material relationships than more traditional archaeological methods. The investigation of adobe materials, in particular, stands to gain much from these perspectives.

This paper brings together data from a broad range of sites within a single region with the goal of determining a set of diagnostic formal and textural patterns for adobe walls and their foundations. We explore techniques for delineating California's buried adobe ruins through site interiography using ground-penetrating radar. This non-intrusive technique has been successful in most of the settings we have applied it. In these cases, we test our assumptions, methodologies, and interpretations where known adobe wall features have been documented through previous archaeological excavations, trench exposure, and historic maps and texts.

Several research themes in the central California geographic area have foci explicitly dependent on the identification and interpretation of adobe features. Historic adobe structures dating between the late 1700s and the late 1800s are present through much of coastal California and inland valleys. Adobe structures ranging in size from small, oneroom dwellings and garden walls to sprawling presidios and mission churches represent a central aspect of California's Spanish, Mexican, and U.S. heritage. For anthropological archaeologists, adobe walls often represent important boundaries between interior and exterior spaces. While larger structures such as major ranchos, churches, presidios, etc., are largely known from historic records, drawings and maps, smaller adobe dwellings were also common in California. These often housed Native people who were variously involved in the mission and rancho systems that prevailed across the coast and inland valleys for generations. It is likely that most buried adobe ruins in California were associated with Native people and households of people from a range of ethnic origins in addition to better known rancho and mission structures. Thus, techniques that allow the more complete documentation of archaeological adobe stand to illuminate a less well-documented aspect 
of California's cultural heritage [7-11]. Given the prevalence of adobe architectural ruins in archaeological sites in other seasonally dry regions, such as the Southwest and Mesoamerica, Europe (cob) the Mediterranean, and Africa (dagga or ferey), the development of subsurface survey techniques for adobe structures has vast archaeological potential. Previous investigations by Conyers [12], Sturm and Crown [13], and others, have demonstrated that adobe walls can be delineated through GPR.

The case studies presented in this paper represent a range of mission-era California archaeological sites, including: three Native American housing adobe room blocks at Spanish missions (Sonoma, San Jose, San Juan Bautista); two Spanish quadrangle compounds, including San Pedro y San Jose Spanish quadrangle (Sanchez Adobe County Park) and Presidio San Francisco; one Mexican period mission compound (Fifth mission complex at Santa Clara); and one newly identified adobe wall at a Mexican and U.S. period Rancho (Castro Adobe in Watsonville)

\section{Materials and Methods}

Interpreting GPR Profiles Showing Adobe Walls: Variables of Field Data Collection

Ground-penetrating radar has grown increasingly common in archaeology, though data interpretation often favors a language which relates positive hits or "anomalies" as targets for excavation over more nuanced interpretation. In this paper, we use an approach known as interiography, or the characterization of variability in GPR data, including composition and configuration of evident features and their context, based on the texture and form of subsurface deposits indicated in radar reflections [7]. This approach emphasizes integration of traditional archaeological methods of feature and stratigraphy interpretation with assessment of variability in GPR data.

GPR data come from pulses of radar energy transmitted into the ground from an antenna on the surface at specified time intervals [4,14]. Figure 1 depicts the general concept of how energy reflected from buried objects, including features or strata, is measured as the magnitude and speed of waves returning to a receiving antenna, often as it is moved along a transect, collecting reflection traces at intervals tallied with a distance encoder (i.e., calibrated survey wheel). The data are then processed by a control unit attached to the receiving antenna that is paired with the sending antenna.

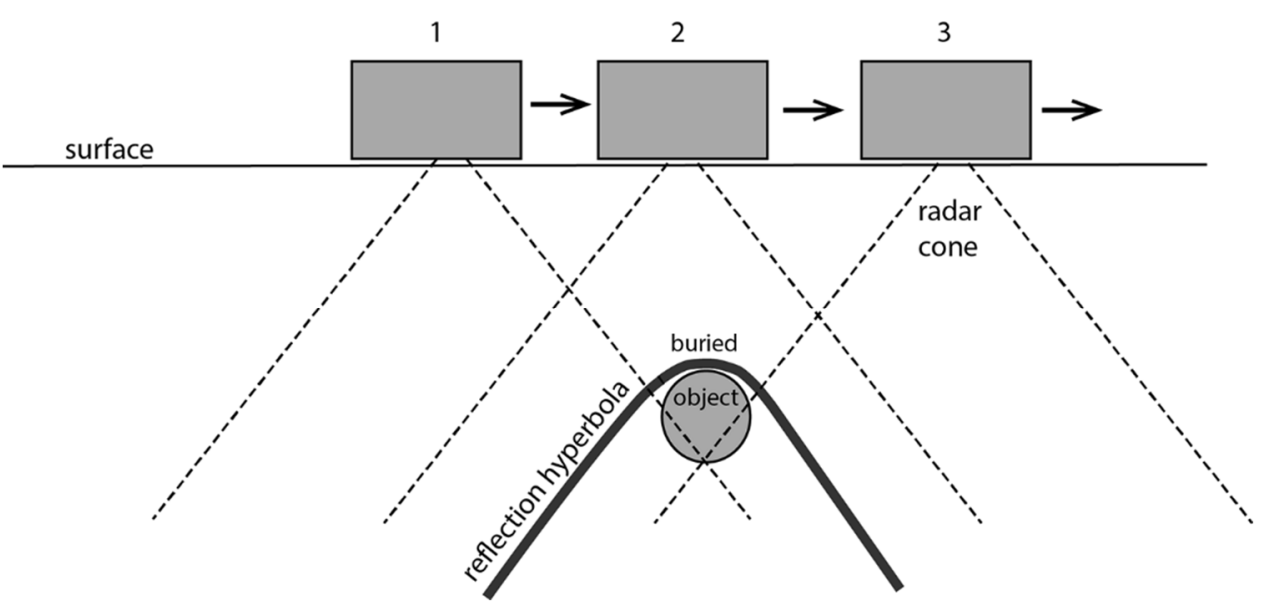

Figure 1. Diagram showing the hyperbola created in a transect profile (radargram) when the antenna crosses a buried object which is farther (1) then closer (2) and then farther (3) from the object.

Radar wave velocity changes for different subsurface materials are determined by physical and chemical properties of the material [4] that determine their electromagnetic properties, or relative dielectric permittivity (RDP). The larger the RDP contrast between two materials at an interface, the stronger the return wave amplitude from that depth. Archaeologists use GPR to examine variation in interior site surfaces or interfaces be- 
tween different materials that portray both the composition and conformity of objects and strata [7].

The GPR data discussed in this paper were collected with a Geophysical Survey Systems SIR-3000 instrument with either a 400 or $900 \mathrm{MHz}$ analog sending/receiving antenna array, or an SIR4000 control unit with a 350HS digital hyper-stacking antenna. Data were processed using open-source software for both profile viewing (GPR Viewer + 2016) and amplitude slice map generation using GPR Process [15], gridded and plotted in Surfer 7.0. Amplitude slice maps incorporate data from multiple adjacent transects collected in a grid at regular intervals ranging from $25 \mathrm{~cm}$ to $50 \mathrm{~cm}$ spacing, depending on antenna frequency and feature depth. Each slice map represents combined data from all transects within a specified depth (or time window) range. Agains-adjusted amplitude color scale appears in some figures.

While amplitude slice maps are often key in determining the depth, position and layout of a feature, analysis of transect radar profiles, or radargrams, is fundamental to site interiography [7]. GPR transect profiles typically show point reflections and planar reflections in numerous variants. A point reflection occurs at a specific point source and appears as a hyperbola, produced because of the conical shape of the radar energy. Planar reflections are more continuous, often resembling stratigraphic transitions from geomorphic profiles. Before assessing object size or feature composition and type from a given scan or radar profile the data should first be described in terms of its texture and its form, including size, shape, orientation, and distribution of distinct reflections [7].

Innovations represented by the newer $350 \mathrm{HS}$ antenna include resolution comparable to that of the $400 \mathrm{MHz}$ analog antenna, but with provision of high-resolution data from deeper within a deposit due to systematic noise filtering (hyper-stacking). In general, individual objects smaller than 5-8 cm diameter in shallow deposits will not resolve distinctly with antennae in the 350-400 MHz range, and clusters of small objects may appear as a single hyperbola. The noise floor or maximum depth range for these antennae, at the sites presented here, was from $80 \mathrm{~cm}$ to $150 \mathrm{~cm}$.

Related to noise and instrument resolution, it is critical to consider the scale of visualized signal returns. Figure 2 shows how scale changes the portrayal of variation in a GPR profile of a wall foundation. Gains, filtering and time-zero adjustment are necessary aspects of GPR data processing $[3,16]$, but they are not detailed in this paper. Key variables include elements making up the profile: soil, melt, conjoined adobe bricks, stone/rubble base, and nearby features and objects (e.g., floors, collapsed roof tiles, collapsed bricks, artifact accumulation). The dimensions and relative positions of elements are variables that are explored through the techniques outlined here. Additionally, there are limiting factors in the data, including radar interference, attenuation at depth, resolution of antenna, complexity of reflectors, metal stacking, and air waves from surface contact conformity and surface objects. In the transect profiles shown here, the scale of the profile has been chosen to allow general comparison of the scale of textural constituents, such as nodes and blocks that likely represent rubble, cobbles and boulders, or adobe bricks within a given linear wall feature.

The orientation of transects and grids with respect to subsurface feature orientation is also important, sometimes requiring multiple passes or overlapped coverage by antennae of multiple resolutions (Figure 3). For the purpose of identifying or confirming the presence of a buried adobe wall feature, it is often best to set up a grid at an angle to the expected linear feature. However, for the purposes of adobe feature analysis, perpendicular and parallel transects, relative to the wall feature, are very informative. Once a likely wall feature has been identified, it is recommended that perpendicular transects be run in multiple locations to further characterize the feature (i.e., comparative interiography).

With these variables of instrument performance, field data collection parameters, and interpretive frameworks, we considered subsurface adobe features in our study area. In the examples which follow, the primary goals of our approach were to (1) trace the extent of known adobe architectural features, and (2) identify previously unknown adobe features. 
Further analysis of feature variability could include distinguishing adobe bricks from foundation rubble, measuring wall width, brick characteristics, etc., distinguishing adobe melt from related floor strata (interior) and outside surfaces, and identifying adobe-related features (such as corredor posts at San Juan Bautista and the chapel altar in the Spanish quadrangle at Sanchez Adobe). In each case, the challenges of identifying and interpreting archaeological adobe deposits benefited from complementary interiographic approaches and field methodologies.
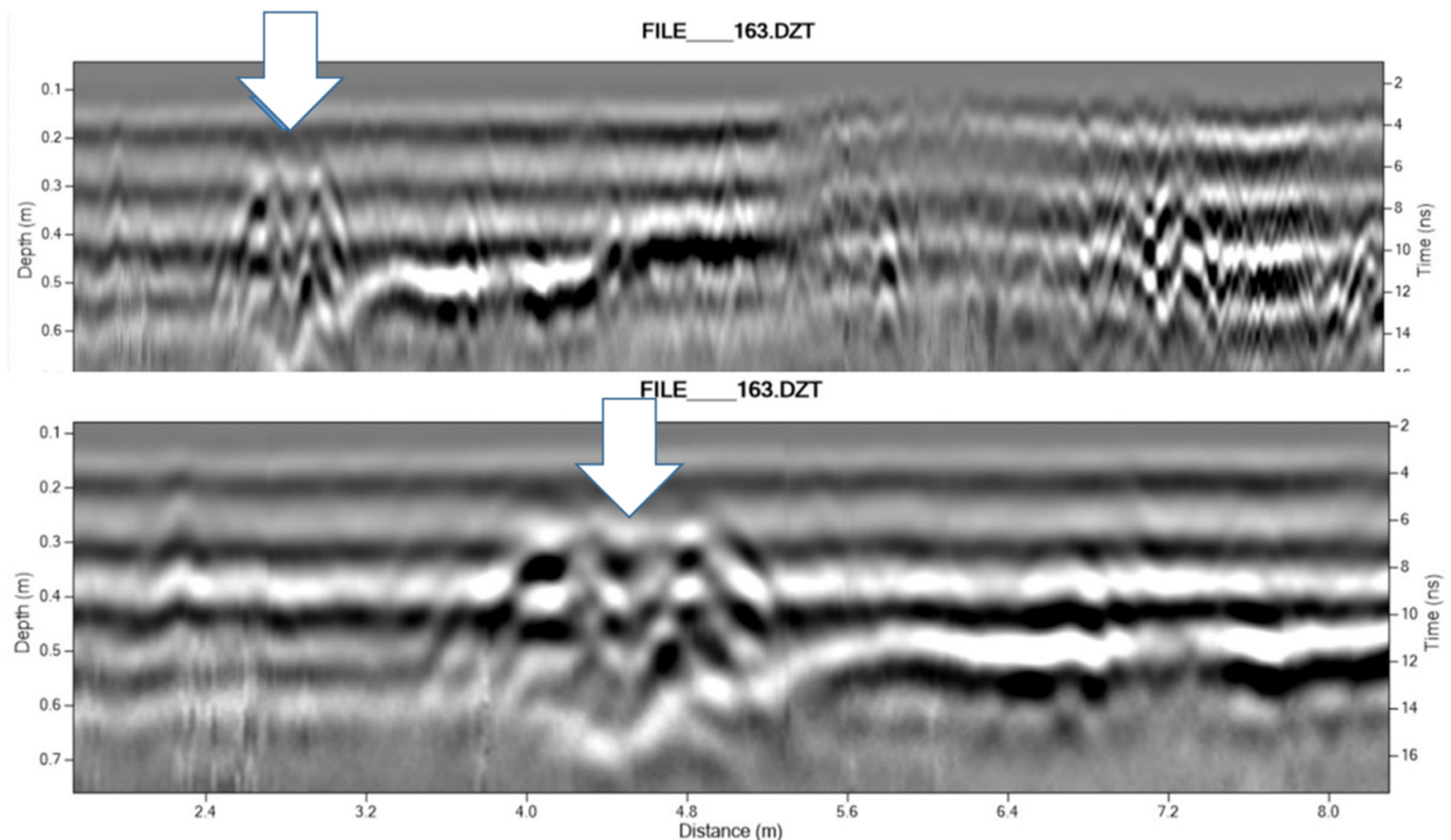

Figure 2. Two versions of a single feature profile at different scales. San Juan Bautista adobe wall crossing and strata.

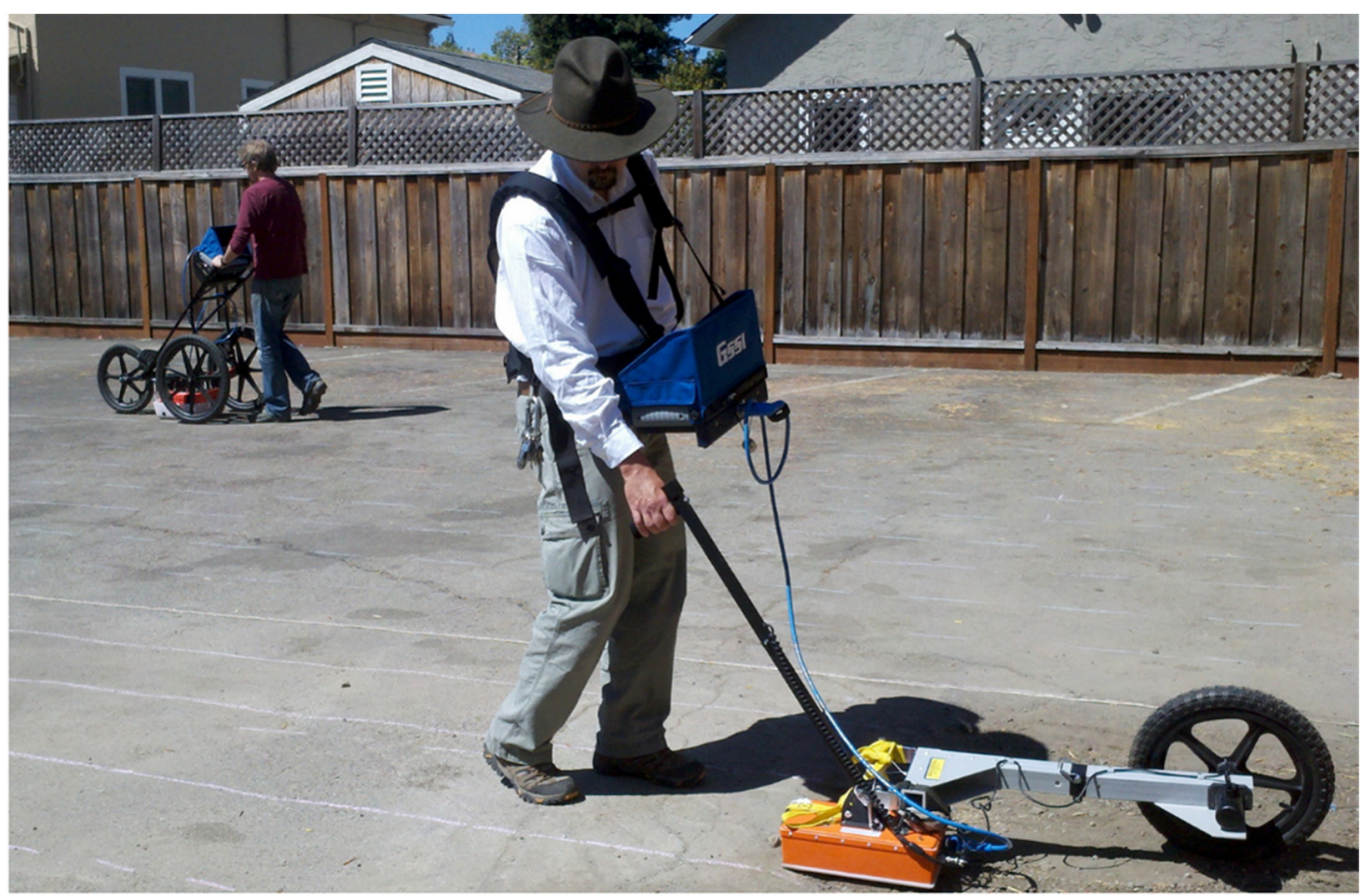

Figure 3. Scanning simultaneously with multiple antennae resolutions and offset grids. 


\section{Results}

\section{Case Studies of Archaeological Sites}

At the site of Mission Santa Clara (Figure 4), now under modern Santa Clara University, the authors conducted GPR surveys in coordination with undergraduate field school excavations conducted by Lee Panich, who has researched the history of the mission complex extensively. The university grew out of the mission complex, which was reconfigured multiple times after its initial construction in the late 18th century.

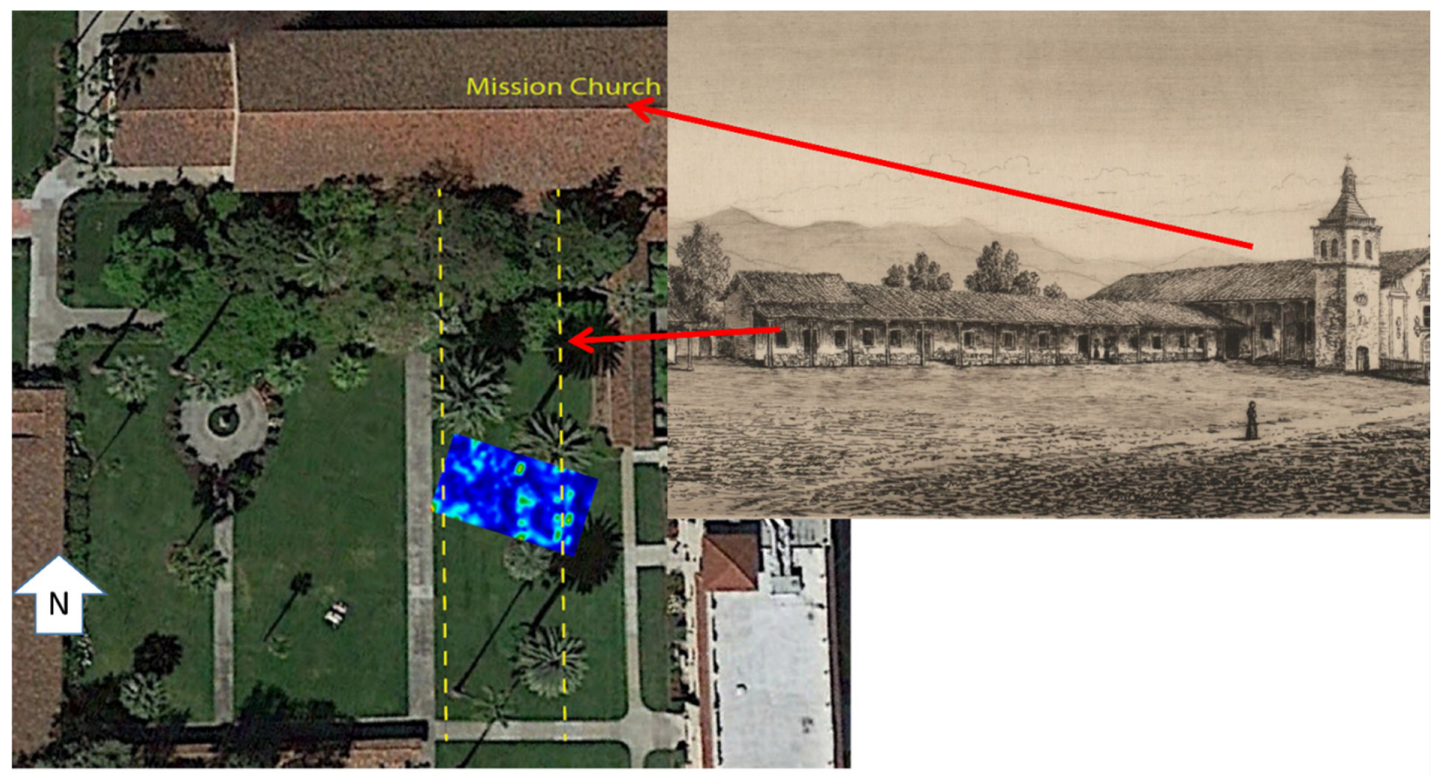

Figure 4. Mission Santa Clara on Santa Clara University campus, with the nearly perpendicular intersection of walls (yellow dashed lines) of the Mission Fathers' residence (Grid 1).

Two GPR grids have been surveyed at the 5th Mission Complex within the campus proper, and each revealed foundations of known adobe structures based on archival texts, maps, and photographs. Figure 5 shows a slice from Grid 1 at the Mission Fathers residence, and a near-parallel transect from this grid. The rubble of the foundation and possibly decomposing bricks are indicated by a cluster of stacked nodes from 8.8 to $9.8 \mathrm{~m}$ in this profile. Because the transect is slightly oblique to the wall, the width of the foundation is slightly exaggerated. Areas of less reflection, east and west of the node cluster, may be builders' trenches or possibly areas cloaked by adobe melt.

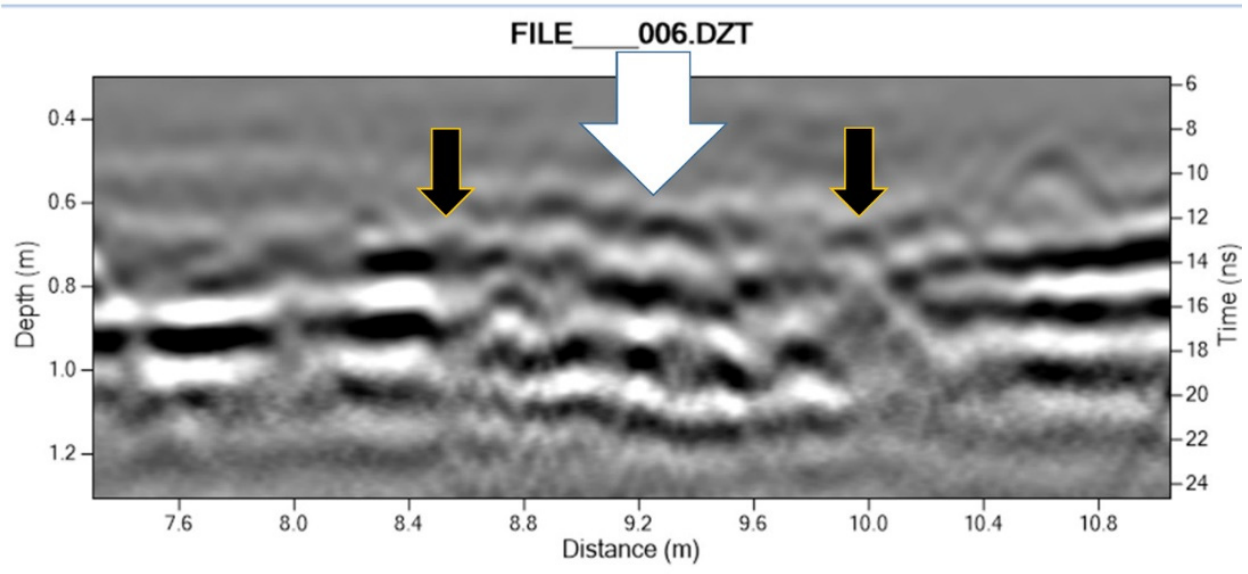

Figure 5. Possible builders' trenches on both sides of the east wall (thick white arrow) at Mission Santa Clara seen as gaps (thinner black arrows) in horizontal strata to left and right in transect using the $400 \mathrm{MHz}$ antenna. 
Grid 2 transects are shown in Figures 6 and 7, also at a known adobe building wall from the 5th Mission Complex (not shown in plan view). While this wall was clear in Grid 2 profiles, it was not clearly represented in slice maps despite numerous interpolation variants attempted, likely due to the large number of blocks, nodes and spheroids of other origin surrounding the wall in most slices. This further demonstrates the importance of analysis of GPR transect profiles in addition to amplitude slice maps for a given grid.

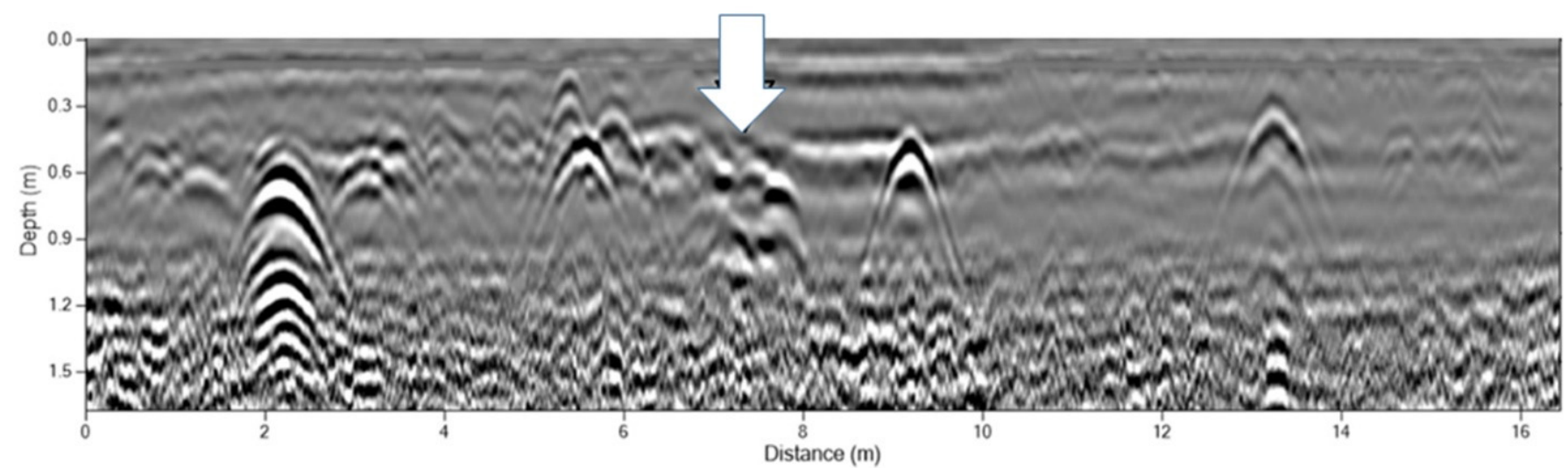

Figure 6. Perpendicular wall crossing at 7-8 $\mathrm{m}$ in Grid 2 transect at foundation of 5th Mission Complex, Mission Santa Clara.

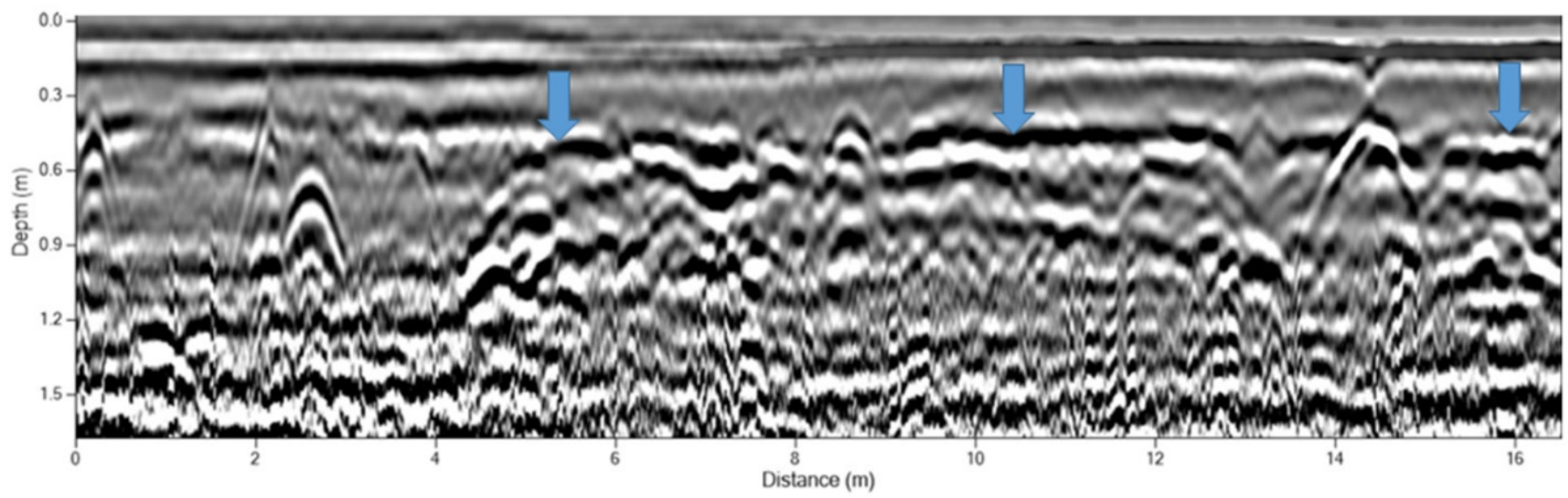

Figure 7. Wall-parallel transect of same feature crossing grid 2 transects seen in Figure 6 . The wall feature at $\sim 50 \mathrm{~cm}$ depth begins at $4.5 \mathrm{~m}$ and continues through end of the transect at $16.5 \mathrm{~m}$.

A feature position can be plotted manually when it is not adequately rendered in slice maps. An additional observation from Santa Clara is that the wall-parallel transect showed less variation in the foundation than the perpendicular wall-crossing transect. This is often but not always the case with buried adobe wall features. It is likely that in the parallel transect, hyperbolae of adjacent blocks and nodes merge into planar reflections when in continuous distribution. Hyperbolae from individual nodes, spheroids and blocks in the perpendicular transects are typically more distinct.

Much closer to the coast, yet contemporaneous with Mission Santa Clara, the Spanish quadrangle known as San Pedro y San Pablo, at what is now Sanchez Adobe County Park in Pacifica, was built in the 1780s at the location of the Native American village Pruristac in the San Pedro Valley. Sometimes known as the "Spanish Farm," the compound was used actively by the Spanish mission system as an outpost for Mission Dolores for less than ten years. Subsequently the three-sided set of room blocks fell into ruin, though in the 1830s a new, two-story, adobe private rancho residence was constructed adjacent to the north wing. Reuse of building components for this and possibly other later structures has been identified through GPR survey and archival map research $[17,18]$. This updated research agenda has expanded greatly on what was known about this site from previous work. In 
1978, archaeological excavations (Figure 8) were conducted at the Spanish quadrangle, exposing a large portion of the southern and eastern room blocks [19]. While adobe bricks are present in some areas, much of the structure was delineated by the presence of foundation stones.

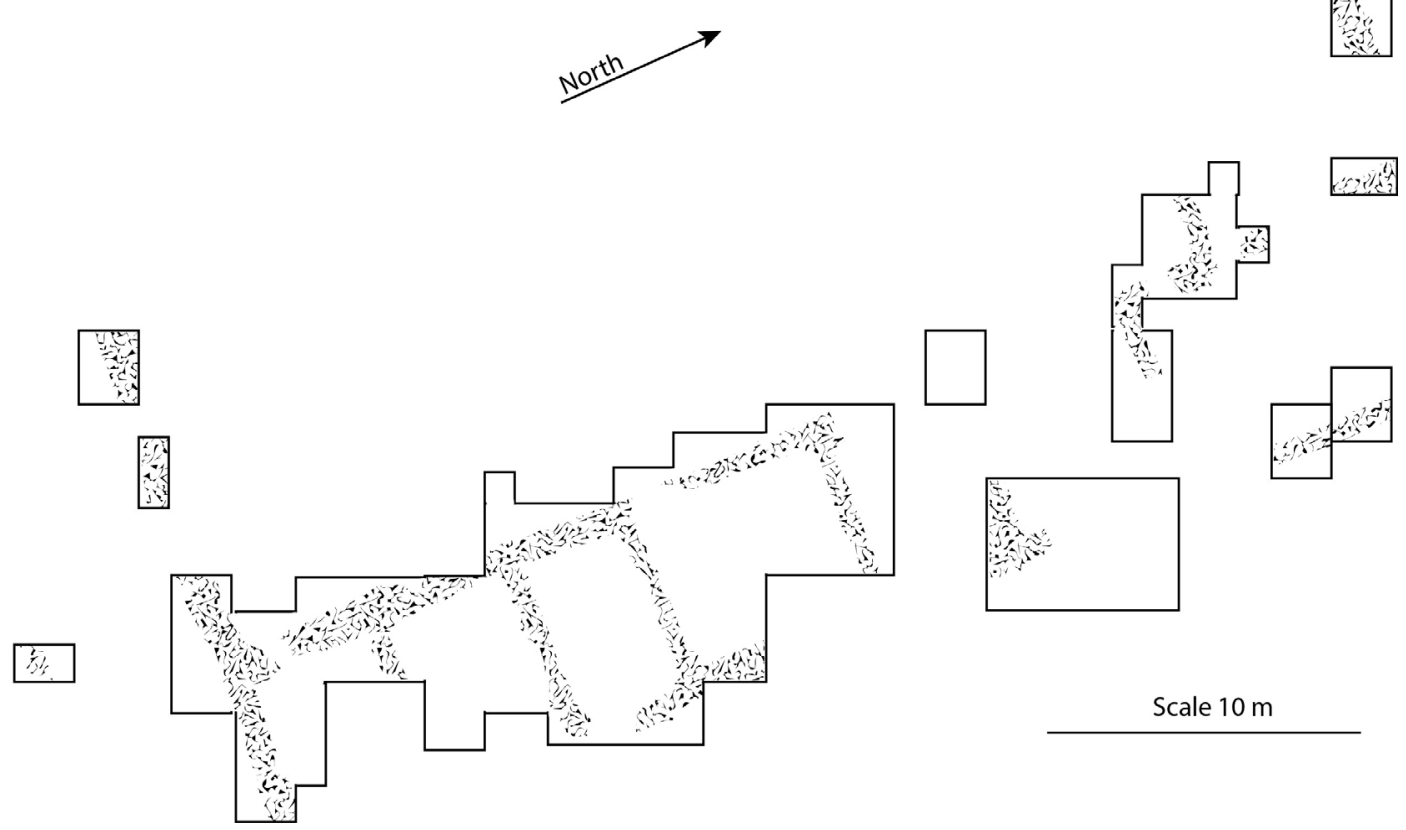

图

Figure 8. The Spanish quadrangle known as San Pedro y San Pablo, at what is now Sanchez Adobe County Park in Pacifica. Excavation map [20].

A 2016 GPR survey (Figure 9) at Sanchez Adobe County Park was part of planning for a proposed interpretive center and expanded parking. While the Spanish quadrangle was not the primary focus of this survey, a portion of the southern room block was surveyed with two GPR grids, and individual transects were collected within the eastern and northern room blocks. Slice maps from the two survey grids clearly show the interior and exterior wall foundations of the southern room block (Figure 10). Figure 11 shows a portion of a GPR transect profile and a grid slice at $45 \mathrm{~cm}$ depth. The profiled transect parallels the exterior wall of the southern room block, intersecting brick and cobble foundation features. Figure 12 shows the $400 \mathrm{MHz}$ antenna profile of a transect at perpendicular crossings of two adobe walls in the north wing of the Spanish quadrangle. Subsurface reflections suggest an interior (adjacent to chapel) wall and a much more robust exterior wall. Thus, relative construction techniques, sequences of accretional building, and differential orientation of architectural elements are more coherently integrated into the subsurface investigation of this period in the park's history. 


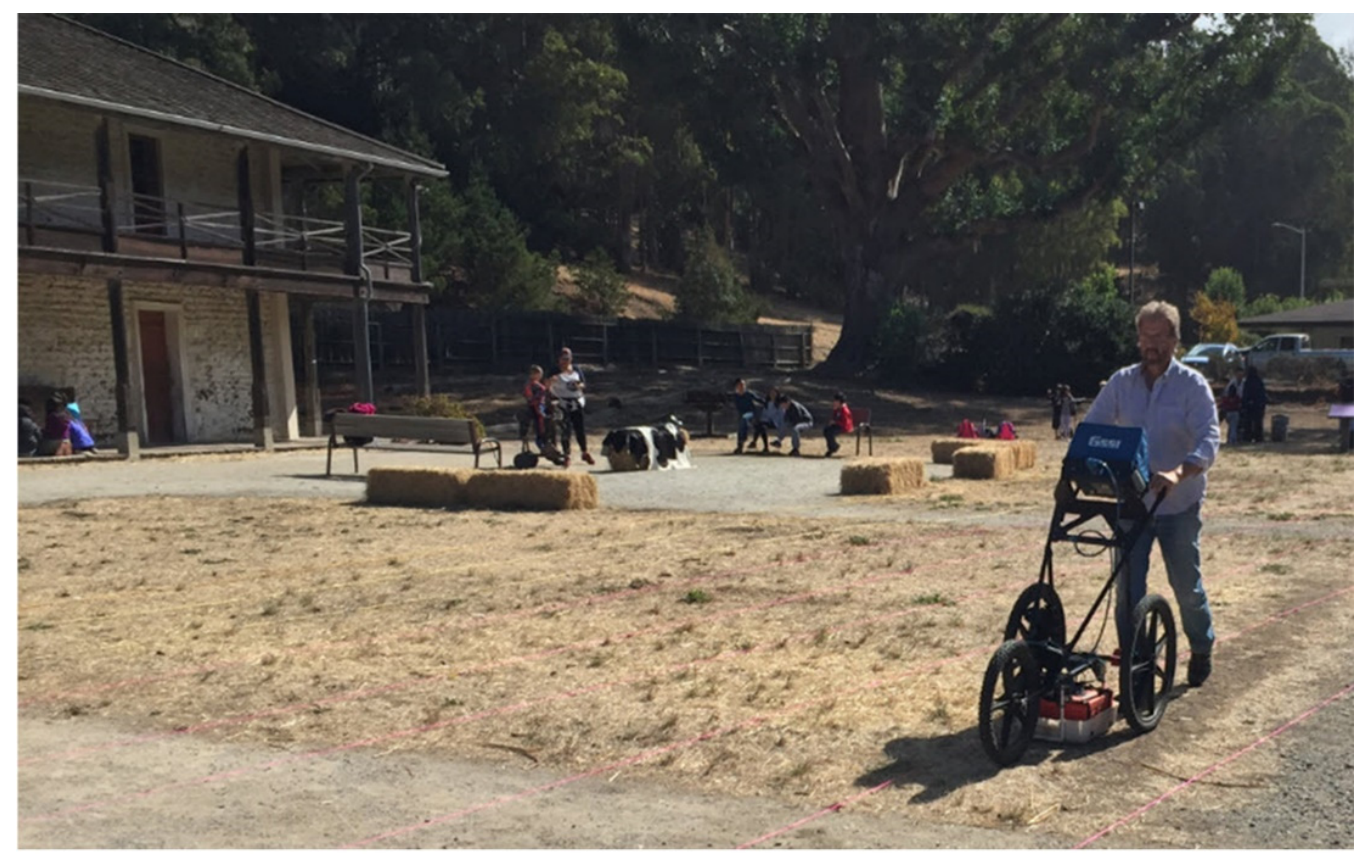

Figure 9. GPR survey of Sanchez Adobe plaza with $400 \mathrm{MHz}$ antenna.

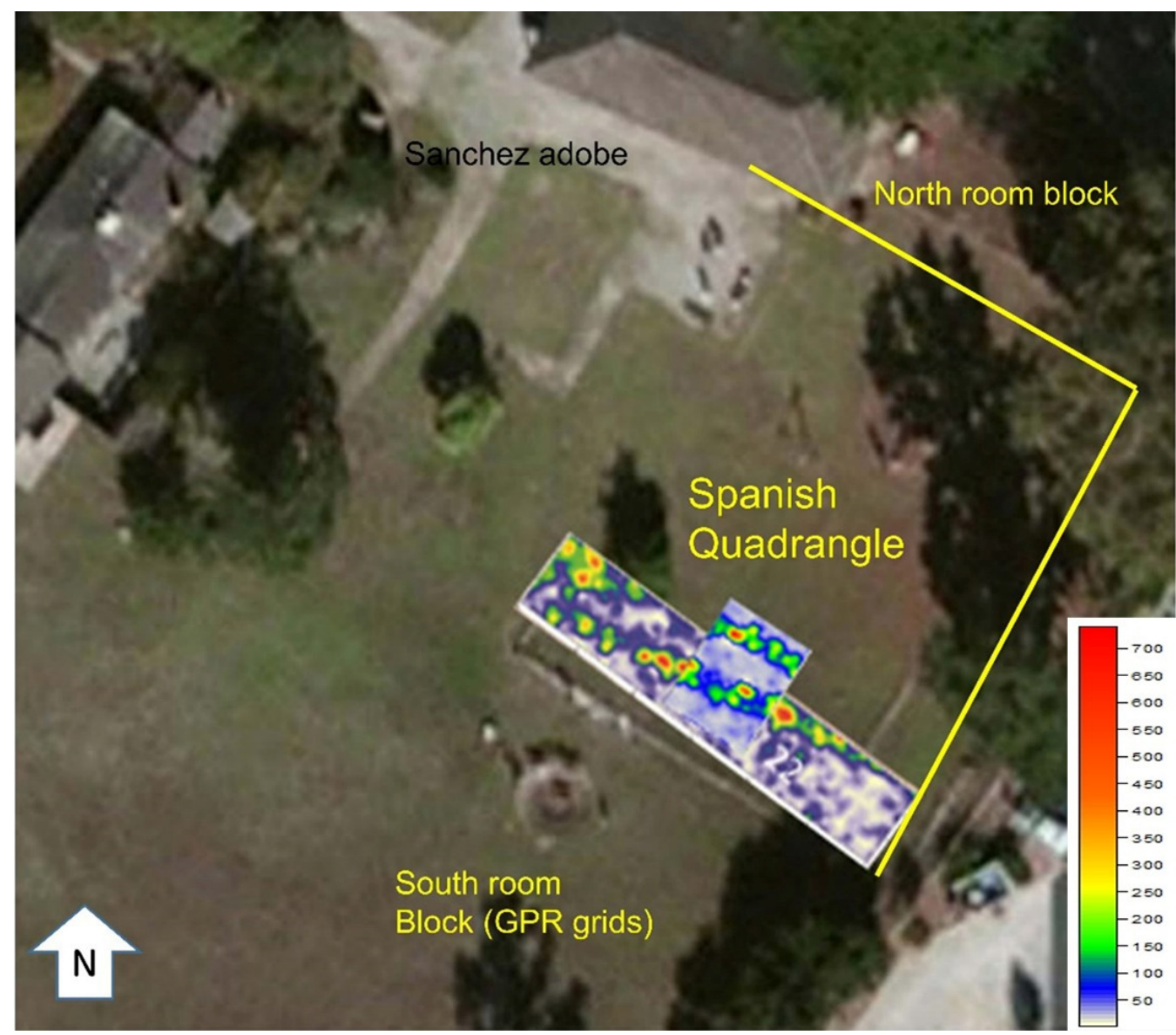

Figure 10. Slice maps highlight subsurface adobe walls of Sanchez Adobe quadrangle. The gainsadjusted amplitude color scale appears in the lower right corner. 


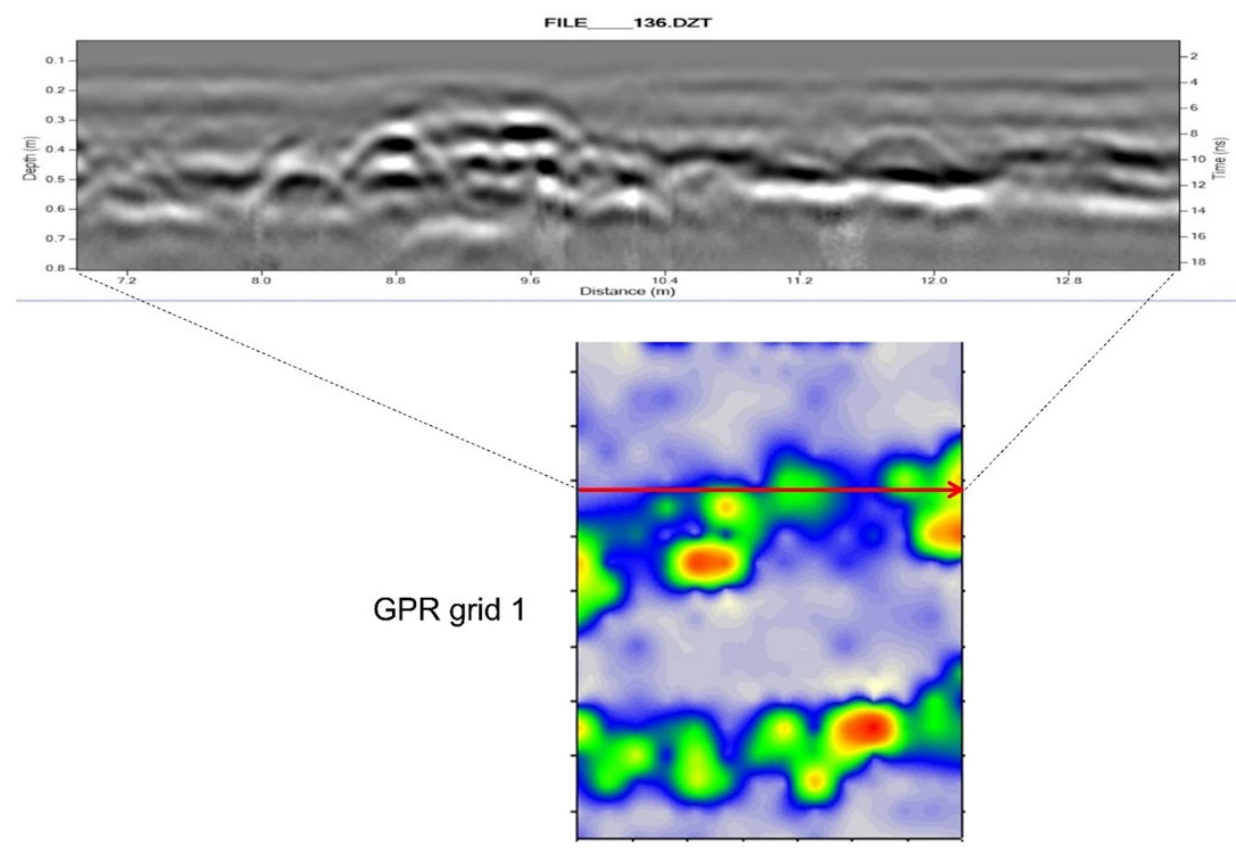

Figure 11. A transect profile paralleling the exterior wall of the southern room block at Sanchez Adobe plaza.

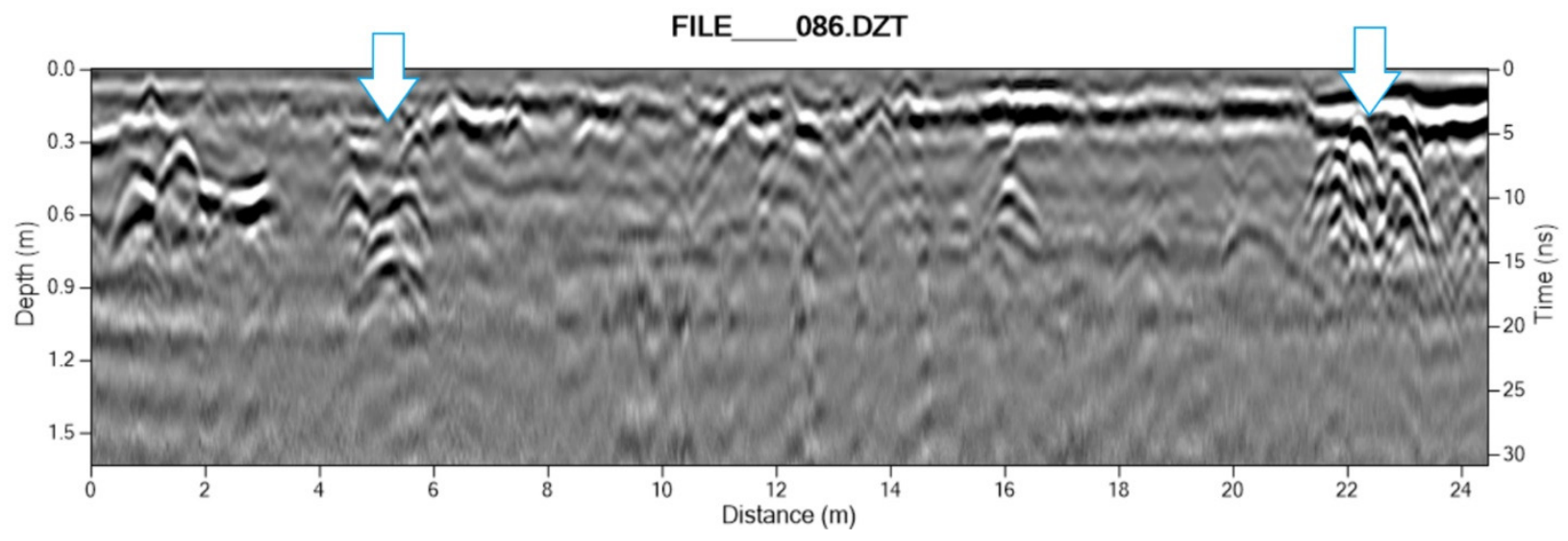

Figure 12. $400 \mathrm{MHz}$ antenna profile of a transect at perpendicular crossings of two adobe walls in the north wing of the Spanish quadrangle at the Sanchez Adobe. The wall at left is interior (adjacent to the chapel) and the wall at right is likely a more robust exterior wall.

A non-invasive survey of Mission San Jose's Native American housing similarly built upon previous investigations in another area of the mission and convent complex, but focused on areas inaccessible to, or prohibitively expensive for, traditional archaeological testing. Archaeological excavations in 2001 at a locale far to the south, within an adjoining but no longer accessible property, [21] and current data recovery efforts to the north, confirm archival descriptions of one-story adobe buildings on stone foundations, some divided into two rooms, with dirt floors and tile roofs. It had been anticipated that excavations conducted in 2015 by ESA Associates might encounter such a feature, similar to that uncovered in the previously excavated areas far to the south, but the actual extension of the Native American housing blocks at this distance had remained untested until that time (Figure 13). Figure 14 illustrates the projected relationship of the 2001 excavated footprint of adobe buildings and loci for potential extensions of known linear alignments in which to survey with GPR in advance of current excavations. This projection assumed that there were a non-contiguous series of buildings in a coordinated linear arrangement, as seems to 
be the case across the street, on either side of the Mission church, and in early depictions (Figure 13).

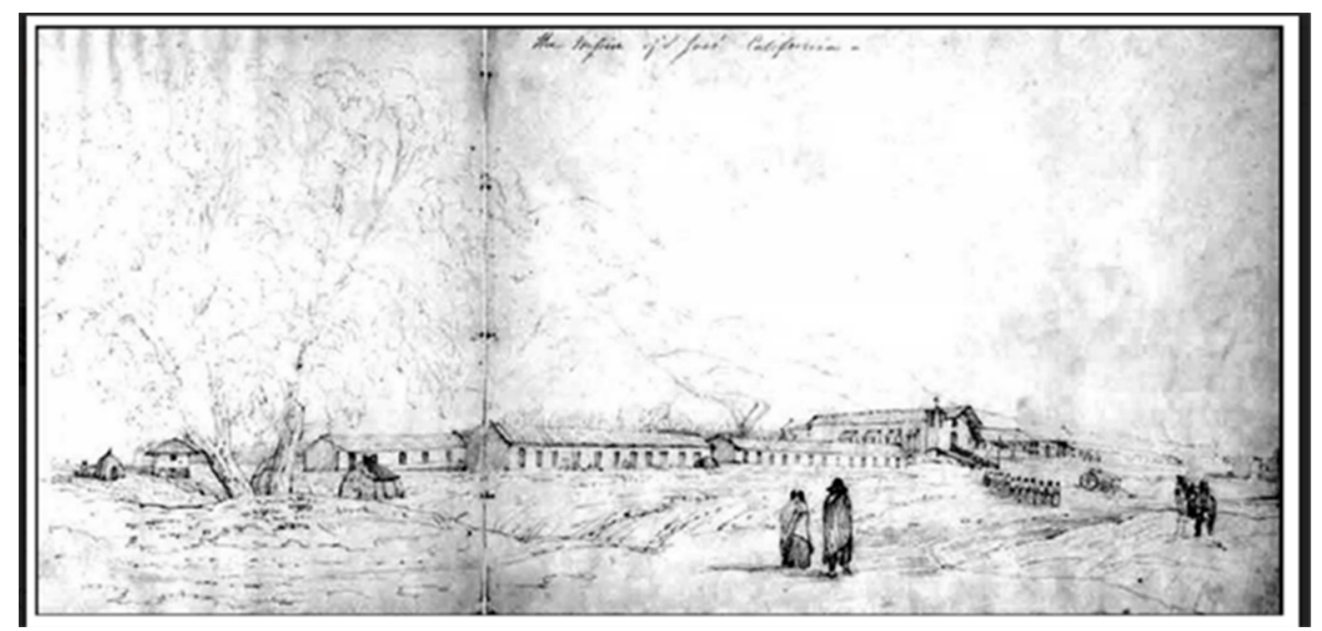

Figure 13. An early depiction of Mission San Jose's long Native American quarters' adobe architecture [22].

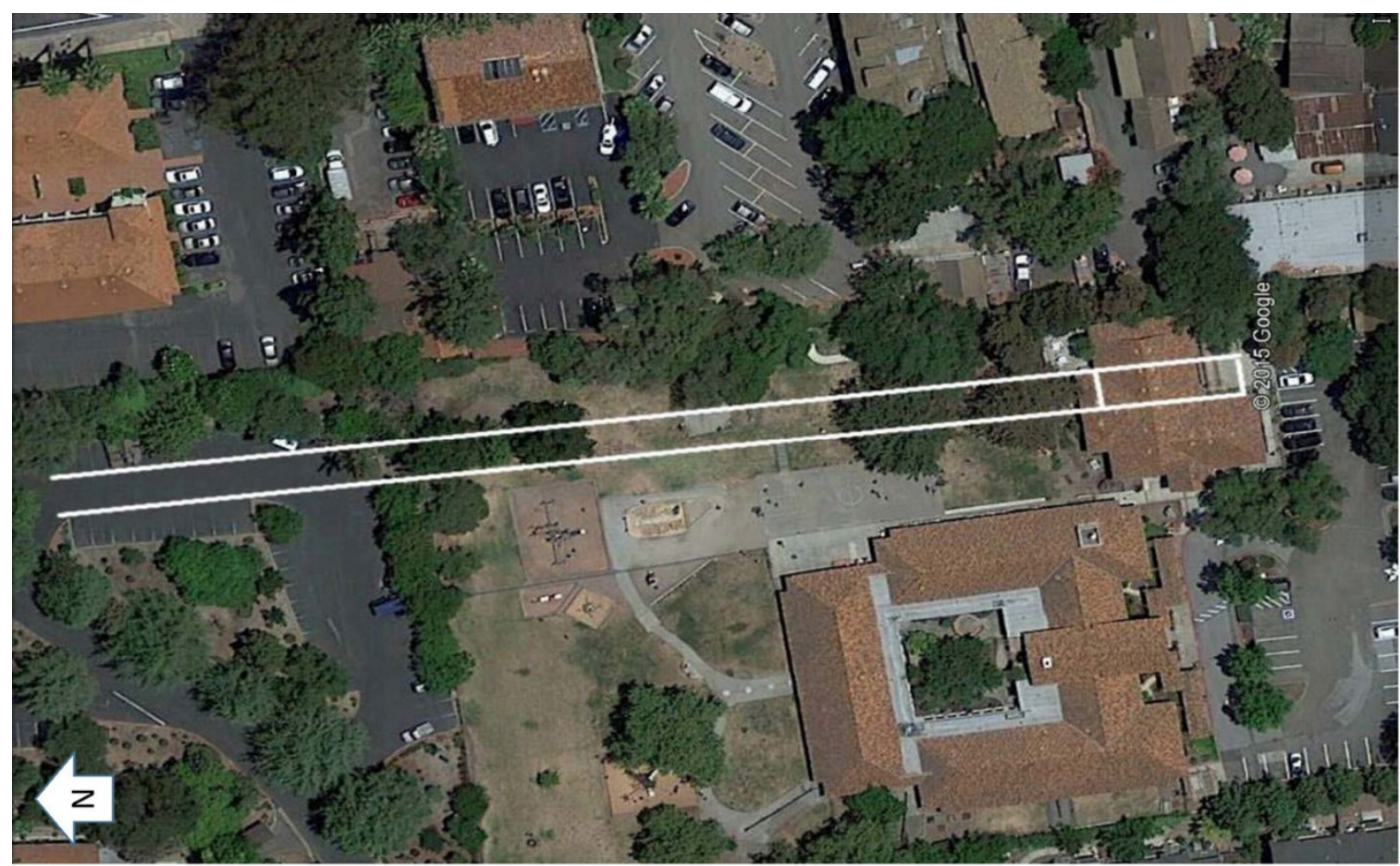

Figure 14. Possible projection of Native American adobe housing from 2001 excavations.

Though documentary evidence suggested two-room blocks of adobe structures, the GPR-detected linear arrangement of subsurface point reflections (Figure 15) corroborated a continuation of the rectilinear arrangement of buildings originating in the neighboring property and stretching towards the mission. In addition, the arrangement of returns suggested the features to be a line of more than two rooms, possibly even longer. Not only was this approach successful in testing for the hypothesized extension of the room blocks, but it was also able to challenge assumptions about how many rooms might be located in a single block or set of room blocks. With precision alignment of datums and survey results, follow-on excavations (Figure 16) were able to focus energies only on the 
architecture and associated refuse concentrations while avoiding extensive damage to present day infrastructure (e.g., lighting, parking facilities) and, most importantly, potential disruption of human interments in the area.

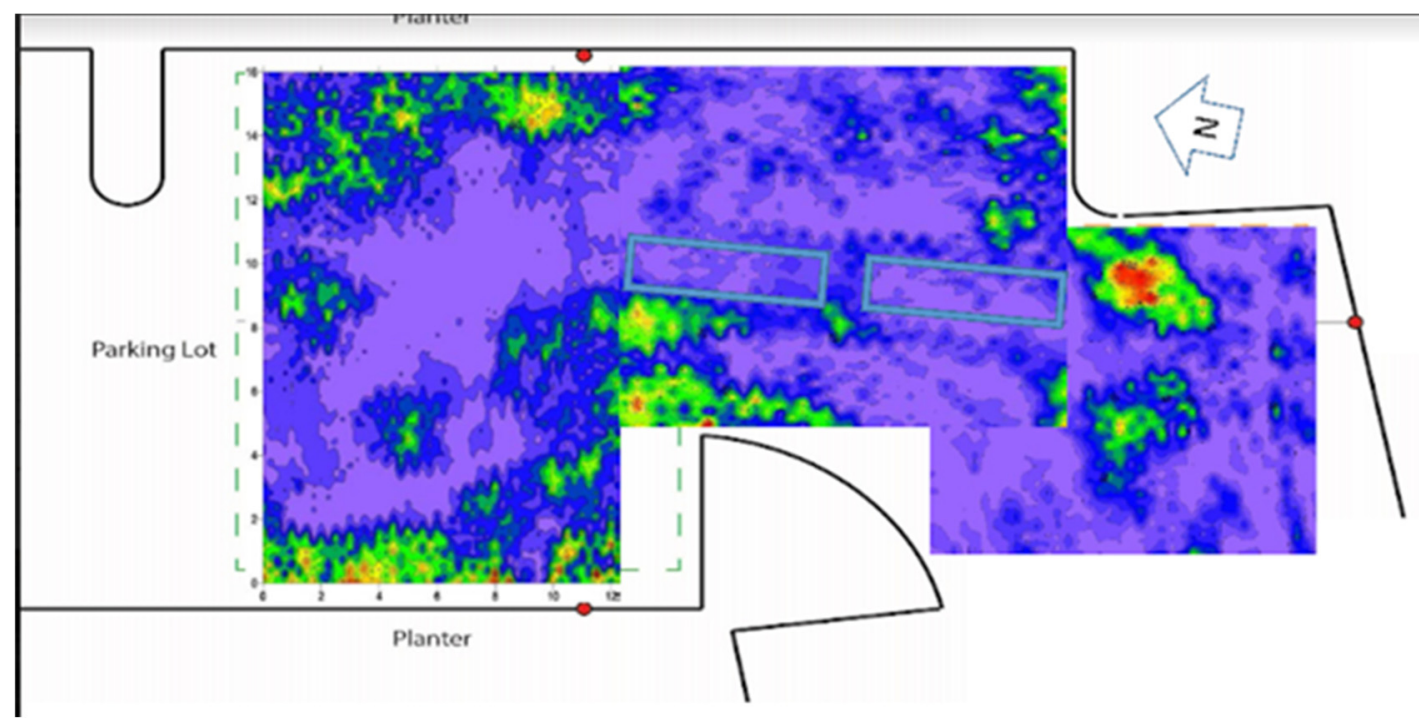

Figure 15. GPR slice map alignment of rectilinear adobe foundation features.

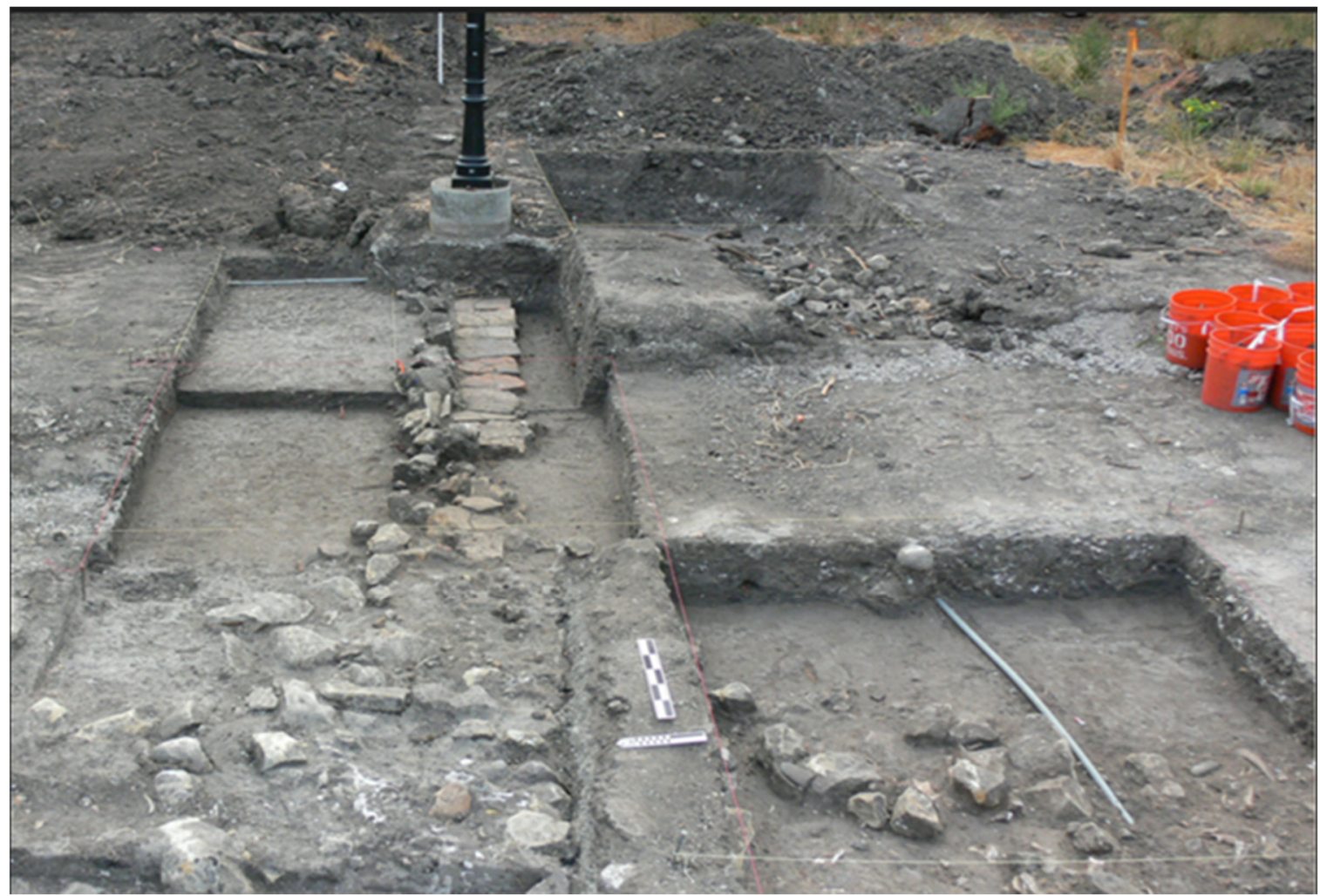

Figure 16. Overview of excavated cobble foundation alignment of adobe housing after GPR survey.

At Mission San Juan Bautista, Native American family housing adobes including the shallow foundation of Building B, a two-row room block, and a more deeply buried Building A, a single-row room block have been identified archaeologically. These structures are preserved on a parcel of State Parks land known as the Taix lot, located at the southern margin of the mission complex at San Juan Bautista. The Native American family housing 
was thought to have been constructed in the 1820s and had fallen into ruins by the 1840s (Figure 17).

The Taix lot survey revealed many elements of adobe foundations including interior and exterior walls of room block buildings, as well as what appear to be corredor posts along the exterior (Figure 18). The position of room blocks closely corroborated previous resistance probe and testing maps [1], providing additional coverage and details. Currently, no known adobe bricks are intact, but sandstone boulders and cobbles making up the foundation are extensive and well preserved. Buried linear adobe wall features appearing in GPR transect profiles are most evident when perpendicular to the transect, though oblique (Figure 19) and parallel crossings (Figure 20) are also informative, but sometimes less clearly identified.

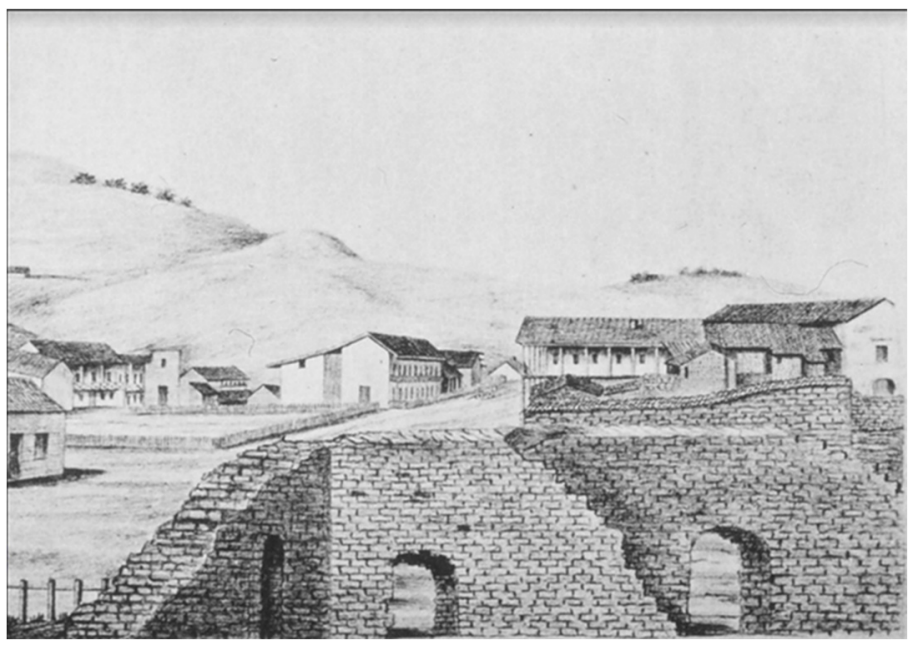

Figure 17. Adobe ruins at San Juan Bautista, 1856 [1].
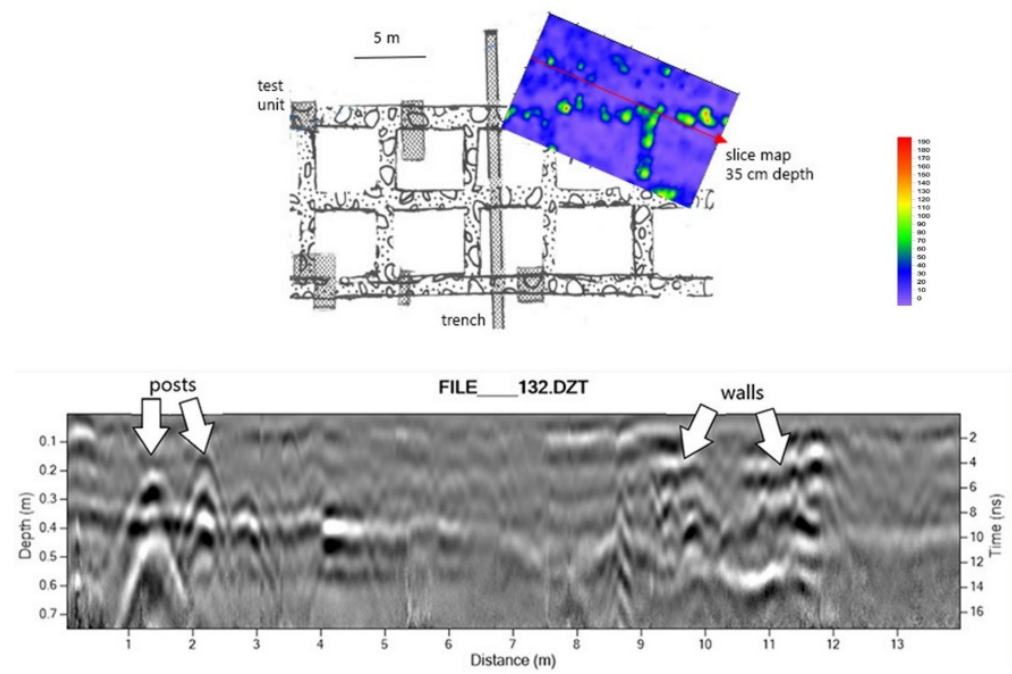

Figure 18. Mission San Juan Bautista, Taix Lot corredor post footings; transect runs from bottom to top of grid crossing walls at 9-10 and 11-12 m. Red line shows location of transect 132. (Base map after [1]). 


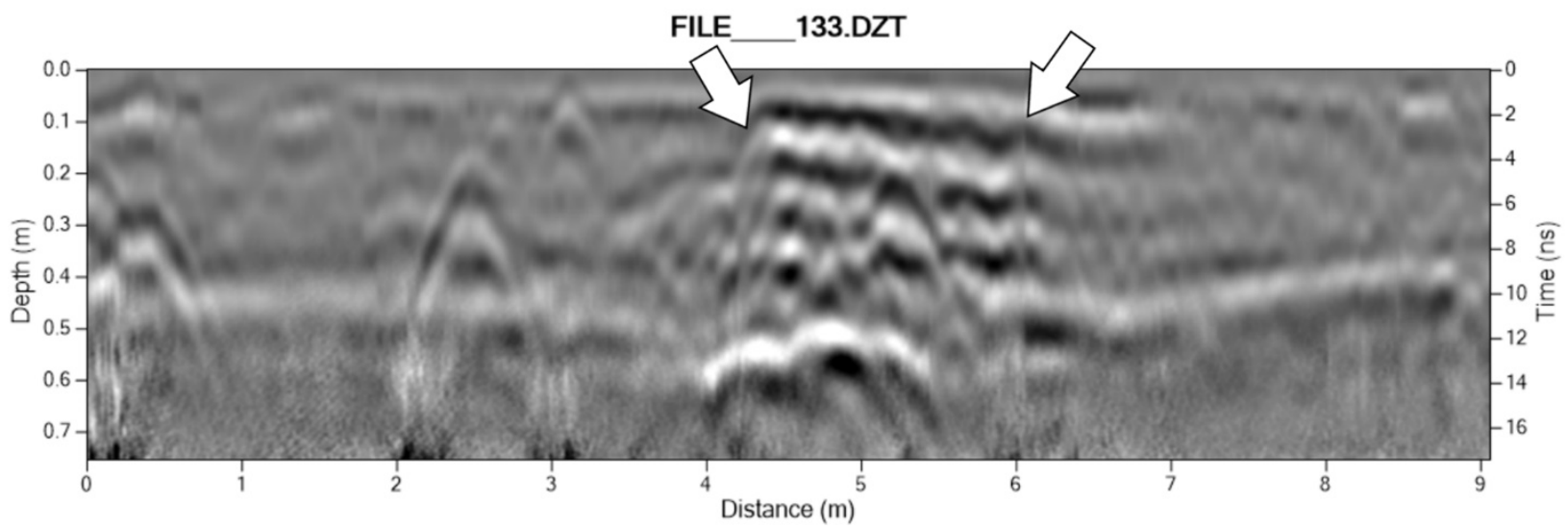

Figure 19. Oblique transect crossing San Juan Bautista Building B wall.

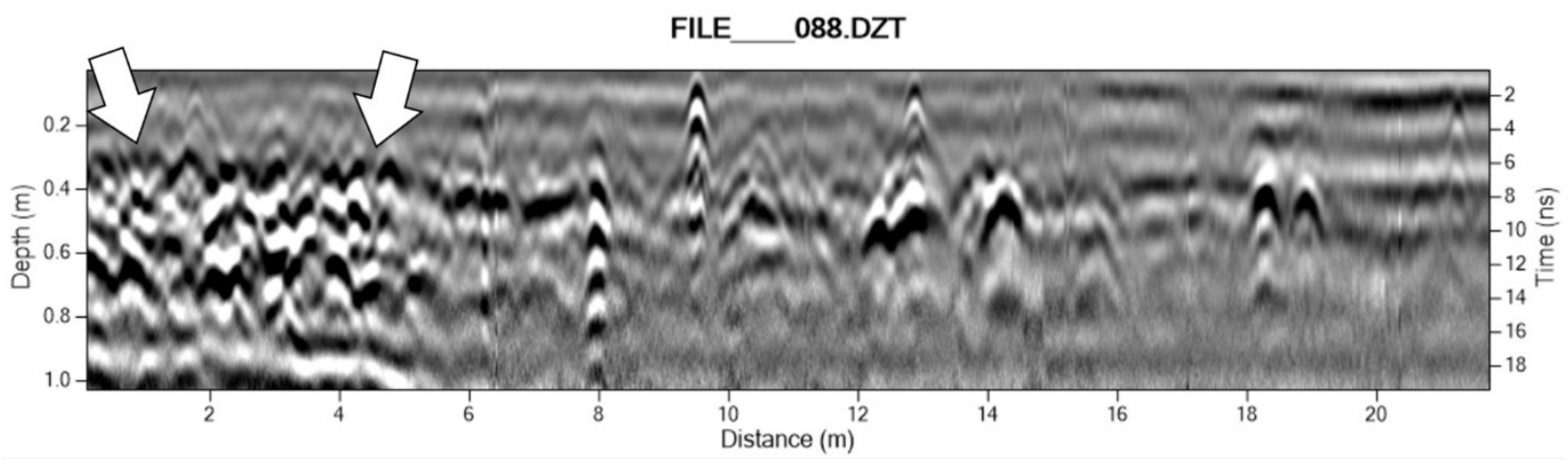

Figure 20. Wall-parallel transect at San Juan Bautista Building B; Rubble and possibly adobe bricks appear as a node cluster at left $(0-4.5 \mathrm{~m})$.

An archaeological GPR survey of the Mission Sonoma northern area is discussed in detail in a more extensive and comparative approach to geophysical interpretation at the site [23]. The partnership between State Parks, UC Berkeley, and the Federated Indians of Graton Rancheria tested the hypothesized extension of mission-era architecture beyond the current wall around park buildings. With a series of overlapped and offset geophysical prospecting grids north of the wall (Figure 21), several subsurface alignments were discerned, despite uneven overburden, clay-rich lenses of matrix, and construction fill. Figure 22 shows a cross-section of a confirmed [2] adobe brick wall over rubble with an adjacent tile floor.

While conforming to the original collaborative mandate to confirm previous assessments about the size and configuration for the buried structure based on subsurface testing and archival estimations, the geophysical survey contributed to refined methodology. In particular, the use of different GPR antennae at the site provided a rapid (compared to the slow resistivity setup and measuring process) and cross-correlated means of detecting foundations, adobe features, and tile floors of the extended mission architectural plan (Figure 22).

Quite different from the religious context of the missions and associated outpost described above, the Presidio San Francisco is located in the northwest corner of the city of San Francisco, just south of the Golden Gate and its iconic bridge, built 160 years later. The first quadrangle was built to house officers and soldiers associated with Mission San Francisco de Asis (Mission Dolores) and Yerba Buena. The adobe structures were reconfigured in the 19th century and some walls were incorporated into existing structures [23]. Ongoing excavations by the Presidio Trust have revealed intact, though partially dissolved adobe bricks underlain by a rubble foundation. Efforts by the National Park Service in 2009 to GPR survey buried adobe foundations at this location were unsuccessful despite the known location of features and good surface conditions. In 2017, we established a 
single GPR grid over an area likely to hold the outer wall of the Presidio quadrangle as well as multiple interior walls. Unlike most other known adobe features, the wall rubble (Figure 23) is evident in the GPR transect profile (Figure 24) but not in much of the grid. The $350 \mathrm{MHz}$ hyper-stacking antenna was particularly useful in this application.

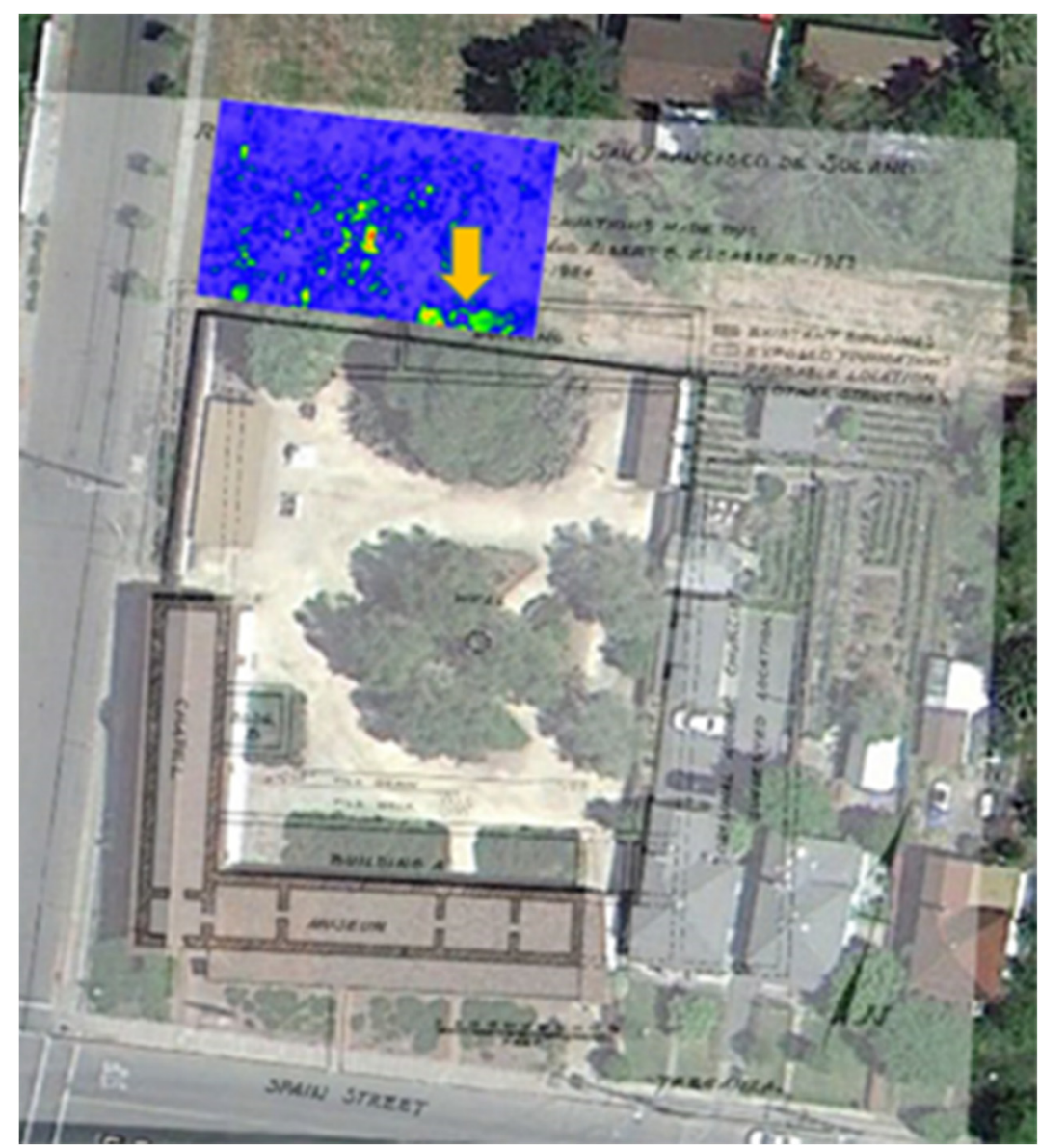

Figure 21. Mission Sonoma GPR survey superimposed on previously excavated units and hypothesized extension of features [8], Figure 9.

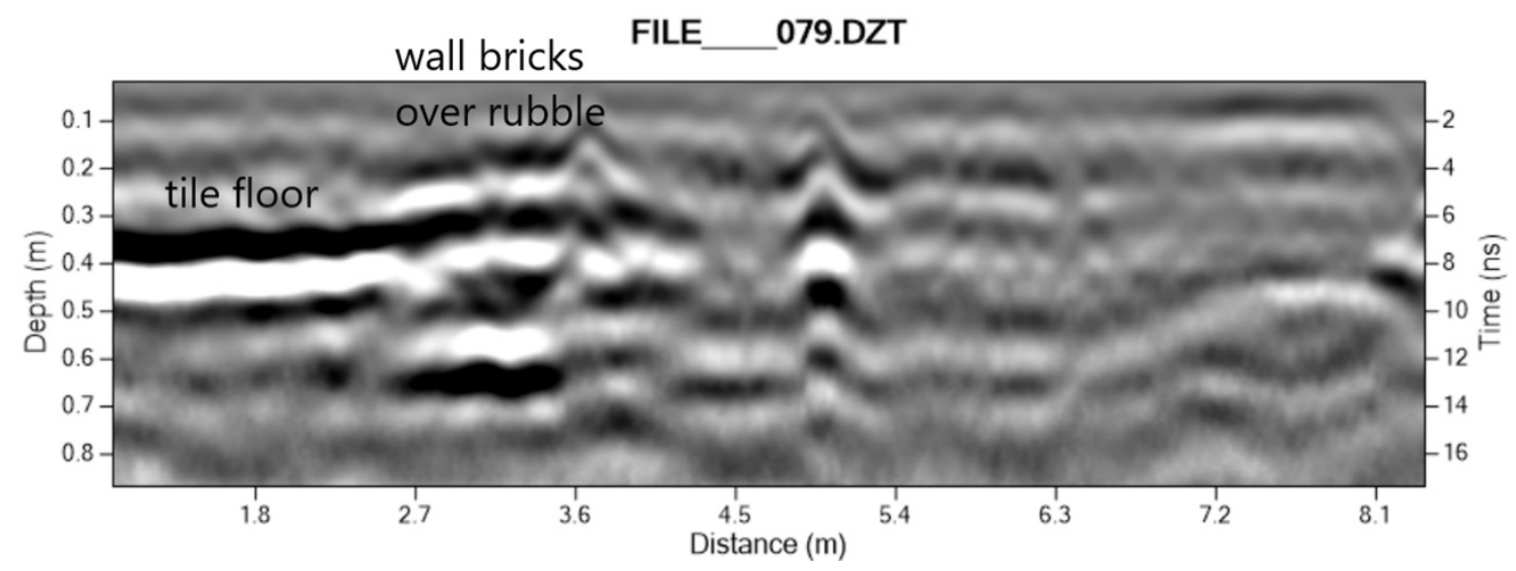

Figure 22. GPR profileshowing Mission Sonoma Building C (tile floor and adobe wall) confirmed through comparisons with 1954 Treganza excavation. 


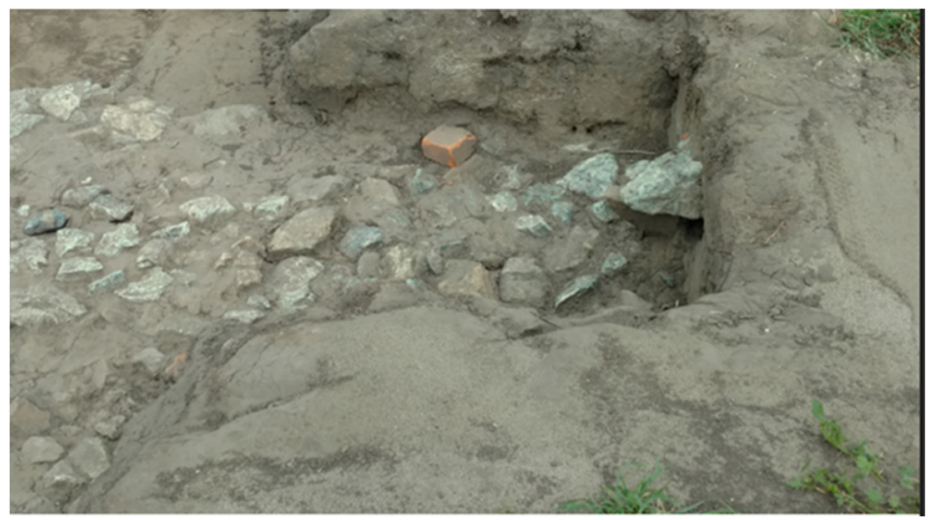

Figure 23. Excavated foundation feature at Presidio San Francisco identified in 2017 GPR survey. The GPR grid was adjacent to this excavation, to the right of this image, showing indications of a continued wall foundation to the north of the excavation.

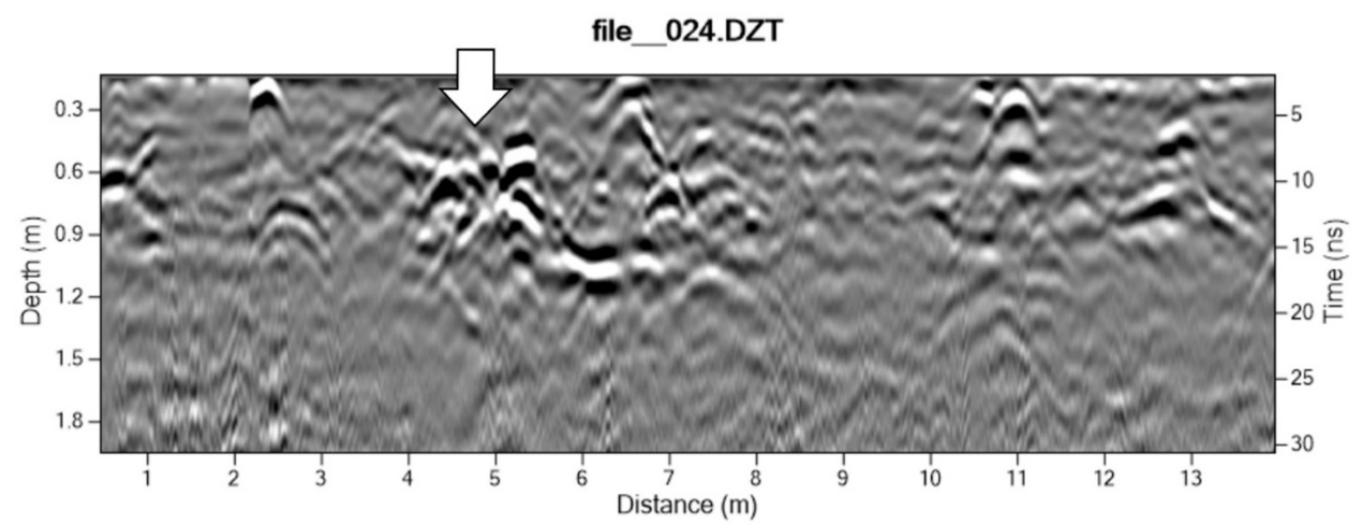

Figure 24. Perpendicular transect crossing of wall at Presidio San Francisco.

The results at Presidio San Francisco demonstrate that GPR survey results should not be used as a basis for concluding that no features are present in a surveyed location. There are many factors that can cloak the presence of wall rubble and other feature components. A stronger case for the absence of adobe wall foundations may be made for grids in sites where patterned reflection features representing adobe walls have previously been identified.

Investigations of other non-religious adobe constructions have also benefitted from a focused application of GPR survey. The Castro Adobe is a standing, two-story adobe dwelling built originally in the early 19th century in conjunction with residential use [24] Research by the University of California Santa Cruz, headed by Sarah Peelo and Tsim Schneider, has the goal of identifying outlying buildings and activity areas, in part to better understand the activities of Native Americans and others who resided away from the main rancho building. Grids to the northeast of the standing adobe have revealed several linear features that may be structural walls (Figure 25). While some of these may be block foundations of later era wooden structures, one feature appears to have the characteristics of an adobe wall foundation (Figure 26). Located in the vicinity of surface adobe bricks, the feature area was partially excavated by field school students in 2017, resulting in confirmation of the presence of adobe melt in the vicinity of the feature. While there is no plan to excavate into further into the adobe matrix, the GPR data and the presence of weathered adobe and dispersed adobe bricks are indications that an adobe structure once stood at this location. Future analysis may determine whether this wall was part of a building or perimeter wall outside the main rancho building. 


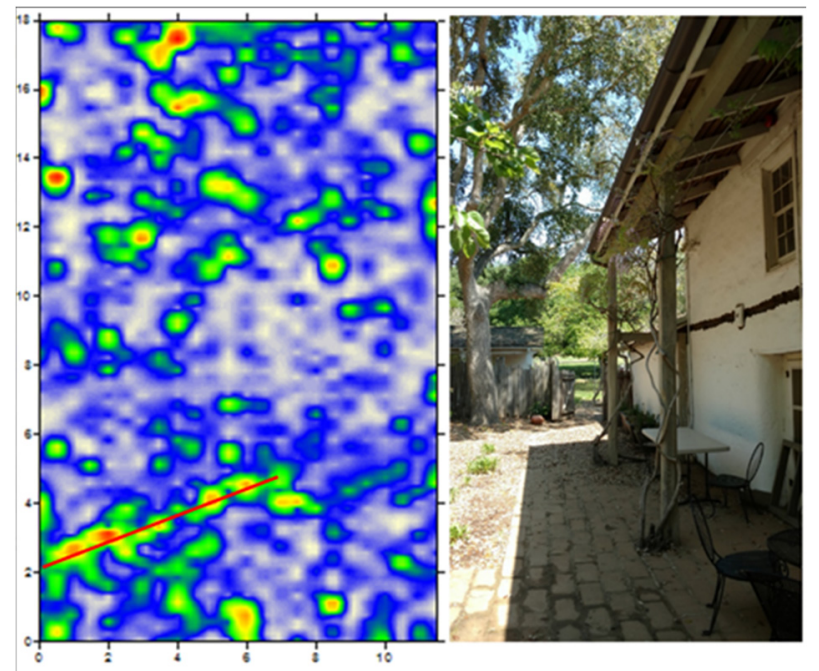

Figure 25. Subsurface features lie adjacent to standing adobe wall at the Castro Adobe, Watsonville.

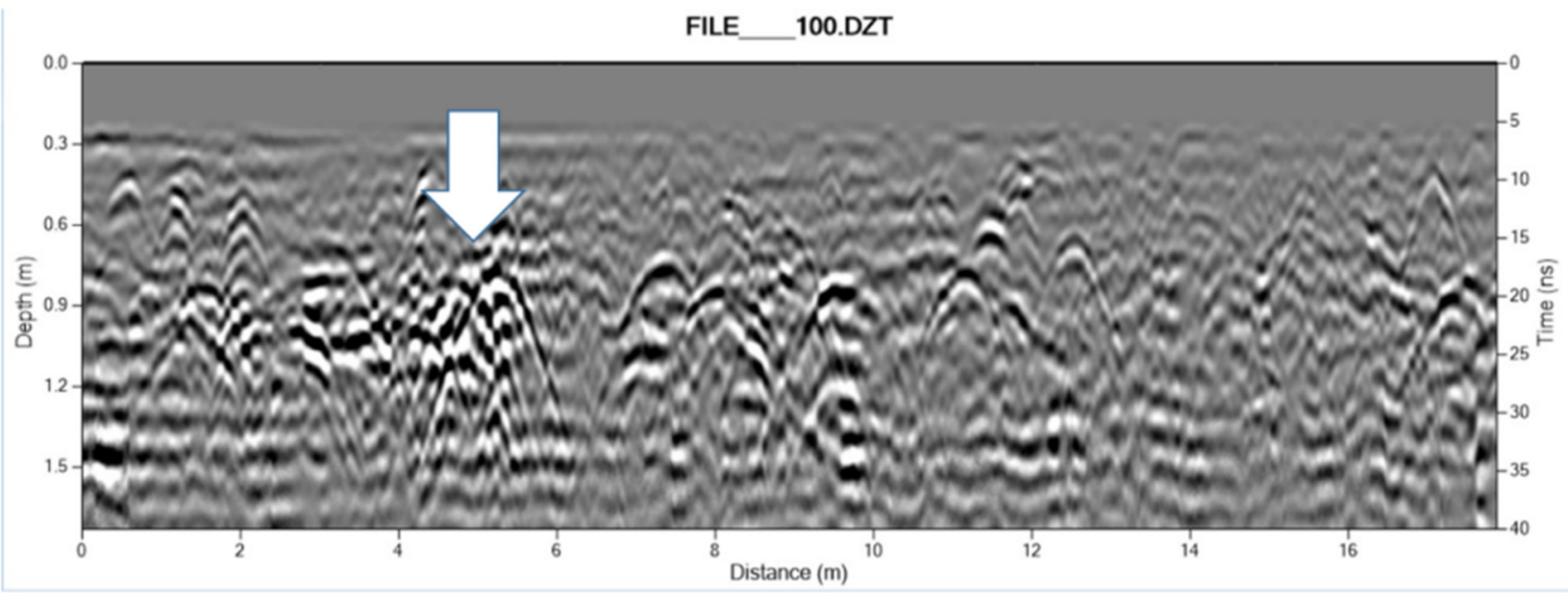

Figure 26. Newly identified by GPR survey, subsurface adobe features are adjacent to standing Castro Adobe wall.

\section{Discussion}

The case studies presented here demonstrate that adobe wall formations are widespread and important feature types recognizable in GPR data from many Spanish, Mexican and early U.S. period sites in California. Often most distinct in perpendicular or oblique crossings in GPR transect profiles, linear adobe features can be detectable via the instrument display of reflection profiles during survey, or later in processed profiles and slice maps at different depths corresponding to time slices. Yet discerning and interpreting these reflections in ways that more closely describe the taphonomic processes acting on subsurface adobe can be challenging because of the similarities in the targeted features and their incorporation in surrounding matrices. Interiographic approaches to feature texture descriptions [7] may assist not only in communicating about emergent features during cross-disciplinary and non-specialist collaborative investigations, but also in more broadly comparative approaches to subsurface signal returns.

Though the nomenclature and its applications to different interiographies are still developing, some examples of feature texture description may include those used to describe GPR survey results at Mission Sonoma (Figure 22). In the transect across a hypothesized location for Building $\mathrm{C}$, nodes or blocks on a plane may represent conjoined architectural elements, as they appear in multiple transects in linear and/or planar formation. Given previous excavations at these depths, and in association with strata known to be sloping 
from this locus to the quadrangle, the point reflections may represent adobe bricks, such as those exposed during earlier excavation. Though these appear to be preserved in a few circumstances at the sites studied, nodes or blocks at varying depths in a linear feature with vertical range likely represent stone/rubble foundation for adobe walls.

In some cases (e.g., Figure 20), both bricks and rubble may be represented in textural patterns evident in GPR reflections. At San Juan Bautista, two vertical sequences (wall crossings) include nodes on a plane over nodes of varying depth. While likely representing adobe brick over a rubble base, this pattern could also represent different types of stonework in the same sequence, or even heat-altered adobe elements in superimposed courses which represent different building sequences or demolition for later extramural space management.

For the analyst interpreting the interiography of interfaces between buried site materials the sometimes multiple node stacks may present with gaps separating each stack, possibly on a plane. In a situation such as that depicted in Figure 19, such a pattern can remain unexplained, but it may involve a combination of adobe with courses of stones. Alternatively, other harder and allied building materials (such as roof tiles) can create a mixed return of reflections resulting from their sequence in site formation processes such as roof collapse. However, in most cases these textural patterns of blocks and nodes are present in aggregate in linear formation as a stack, occurring at a depth greater than surrounding cultural deposits.

Tentatively, we can propose that adobe brick courses may be identified as blocks aligned in both perpendicular and parallel transects (relative to the linear wall feature). Underlying strong point reflections, as nodes and blocks in linear arrangement might then be described and interpreted as stones arranged in courses. A more challenging complex of vertical aggregations, as reflections less systematically distributed among nodes and spheroids within linear features, may indicate stacked rubble foundations. As with several of the presented examples, offset GPR grids, surveyed by antennae of differing resolution, may aid in discerning the size of those reflections, as well as their orientation and extent, more tightly delimiting the range of interiographic interpretations at those loci.

\section{Conclusions}

The analysis of adobe with GPR has significant advantages over excavation for locating and mapping these cultural features. Linear features consisting of stacked elements are often distinct in reflection in a way that may or may not present as readily discernible differences in matrix upon exposure during excavation. Changes in density and dielectric values between "melt" and formed block elements can sometimes be registered by the instrument more readily than by changes in trowel pressure and color. Unlike some geophysical instrument techniques, GPR shows depth and textural variability within a deposit allowing a more expansive interiography. Using GPR to define site structure in conjunction with excavation enhances research into this form of architecture. It also provides much more extensive and complementary information without further site disturbance.

The ability to define large features between excavations, trace strata between excavations or exposures, and define stratigraphic sequences sets the stage for a more comprehensive approach to sites where adobe remains are present beneath the surface. As GPR-surveyed wall sample size increases, variation within this feature type will be more evident with or without excavation. Importantly, open data sharing by practitioners, including raw.dzt files, excavation profiles and feature maps, will provide more replicable studies of ground-truthed interiography. This has potential for future geophysical signal processing collaborations that may at some point correlate different suites of reflection data into more robust categories of subsurface variability.

Innovative approaches to studying adobe such as GPR interiography can provide more comprehensive site investigations while substantially reducing impacts to sites where trenching or testing would otherwise be needed to locate features and delineate strata. As GPR increasingly becomes a part of everyday archaeological practice, linear features such 
as adobe walls will come to define site interiors, much like a stratigraphic profile exposure is a basis for delineating chronological components. The light footprint and comparative speed of GPR survey point to expansive applications of this remarkable technology in archaeology for the foreseeable future.

Author Contributions: Conceptualization for the work was equal for the authors. S.B. and J.U.S. made methodological contributions, executed field data collection from the archaeological sites, took on aspects of formal analysis, investigation, funding, resource management, data curation, and writing. Software and validation was led by S.B.; S.B. and J.U.S. worked on drafts, review, and editing. All authors have read and agreed to the published version of the manuscript.

Funding: The 2012 Braun Endowment of the Archaeological Research Facility, UC Berkeley, supported the purchase of one of the GSSI Inc. instruments used in some of the experiments described in this work.

Data Availability Statement: GPR datasets are retained by the authors.

Acknowledgments: We are deeply indebted to Lawrence Conyers, who gave generously of his time, software resources, and mentorship, as well as our colleagues from Native California, whose ancestral lands we were fortunate enough to be invited to visit for these studies, the Archaeological Research Facility, State Parks, Public and Private Agencies whose partnerships made this work possible: Lee Panich, Sarah Peelo, Glenn Farris, Matt Dietrich, Rae Schraeder, Kari Jones, Glenn Farris, Tsim Schneider, Kyle Brudvik, Rebecca Allen, Matt Russell, Scott Baxter, Susan Brazer, Andy Galvan, Kent Lightfoot, Breck Parkman, Nick Tipon, and Peter Nelson.

Conflicts of Interest: The authors declare no conflict of interest.

\section{References}

1. Farris, G.J. Taix Lot Indian Family Housing Site, Mission San Juan Bautista; California State Parks: Sacramento, CA, USA, 2015.

2. Treganza, A.E. Sonoma Mission: An Archaeological Reconstruction of the Mission San Francisco de Solano Quadrangle. In Papers of the Kroeber Anthropological Society; Department of Anthropology: Berkeley, CA, USA, 1956.

3. Conyers, L.B. Interpreting Ground-Penetrating Radar for Archaeology; Left Coast Press: Walnut Creek, CA, USA, 2012.

4. Conyers, L.B. Ground-Penetrating Radar for Archaeology; Altamira Press: Walnut Creek, CA, USA, 2013.

5. Conyers, L.B. Analysis and interpretation of GPR datasets for integrated archaeological mapping. Near Surf. Geophys. 2015, 13, 645-651. [CrossRef]

6. Conyers, L.B. Ground-Penetrating Radar for Geoarchaeology; John Wiley \& Sons: Hoboken, NJ, USA, 2016.

7. Sunseri, J.U.; Byram, S. Site Interiography and Geophysical Scanning: Interpreting the Texture and Form of Archaeological Deposits with Ground-Penetrating Radar. J. Archaeol. Method Theory 2017, 71, 1400-1424. [CrossRef]

8. Hoover, R.; Costello, J. Excavations at Mission San Antonio 1976-1978; Institute of Archaeology, University of California: Los Angeles, CA, USA, 1985.

9. Lightfoot, K.G. Indians, Missionaries, and Merchants: The Legacy of Colonial Encounters on the California Frontiers; University of California Press: Berkeley, CA, USA, 2005.

10. Panich, L.M. Archaeologies of Persistence: Reconsidering the Legacies of Colonialism in Native North America. Am. Antiq. 2013, 78, 105-122. [CrossRef]

11. Schneider, T.D.; Panich, L.M. Native agency at the margins of empire: Indigenous landscapes, Spanish missions, and contested histories. In Indigenous Landscapes and Spanish Missions: New Perspectives from Archaeology and Ethnohistory; Panich, L.M., Schneider, T.D., Eds.; University of Arizona Press: Tucson, AZ, USA, 2014; pp. 5-22.

12. Conyers, L.B.; Cameron, C.M. Ground-penetrating Radar Techniques and Three-dimensional Computer Mapping in the American Southwest. J. Field Archaeol. 1998, 25, 417-430.

13. Sturm, J.O.; Crown, P.L. Micro-Scale Mapping Using Ground-Penetrating Radar An Example from Room 28, Pueblo Bonito, Chaco Canyon, New Mexico. Adv. Archaeol. Pract. 2015, 3, 124-135. [CrossRef]

14. Conyers, L.B.; Goodman, D. Ground-Penetrating Radar: An Introduction for Archaeologists; AltaMira Press: Walnut Creek, CA, USA, 1997.

15. Conyers, L.B.; Lucius, J.E. Velocity Analysis in Archaeological Ground-Penetrating Radar Studies. Archaeol. Prospect. 1996, 3, 25-38. [CrossRef]

16. Conyers, L.B. Ground Penetrating Radar. In Remote Sensing in Archaeology: An Explicitly North American Perspective; Johnson, J.K., Ed.; University of Alabama Press: Tuscaloosa, AL, USA, 2006; pp. 131-160.

17. Byram, S. Report on Ground-Penetrating Radar Investigations at Sanchez Adobe Park; San Mateo County Parks: Redwood City, CA, USA, 2014. 
18. Wright, C.; Brudvik, K. Results of Additional (Phase II) Ground-Penetrating Radar Survey at Sanchez Adobe, 1000 Linda Mar Boulevard, Pacifica, San Mateo County, California Project Number 16-03324. District IV, Mid Coast District: County of San Mateo. 2016. Available online: https:/ / www.cityofpacifica.org/about/history/adobe/default.asp (accessed on 25 November 2021).

19. Thompson, R. Phase I Cultural Resources Assessment for the Sisters of the Holy Family Project APN: 513-0505-034-00, 159 Washington Boulevard, Fremont, California. Robson Homes. 2013. Available online: https://www.sistersoftheholyfamily.com/ (accessed on 25 November 2021).

20. Dietz, S.A. Report of Archaeological Investigations at Sanchez Adobe Historical District; San Mateo County Parks: Redwood City, CA, USA, 1979.

21. Smyth, W.; Beechey, F.W. An Account of a Visit to California, 1826-1827: Reprinted from a Narrative of a Voyage to the Pacific and Beering's Strait Performed in his Majesty's Ship Blossom under the Command of Captain FW Beechey, in 1825,'26,'27,'28. Book Club of California; Grabhorn Press: San Francisco, CA, USA, 1826.

22. Voss, B.L. The Archaeology of El Presidio de San Francisco: Culture Contact, Gender, and Ethnicity in a Spanish-Colonial Military Community. Ph.D. Thesis, University of California Berkeley, Berkeley, CA, USA, 2002.

23. Byram, S.; Lightfoot, K.G.; Cuthrell, R.Q.; Nelson, P.; Sunseri, J.U.; Jewett, R.A.; Parkman, E.B.; Tripcevich, N. Geophysical Investigation of Mission San Francisco Solano, Sonoma, California. Hist. Archaeol. 2018, 52, 242-263. [CrossRef]

24. Peelo, S. Presentation. In Community Archaeology at Rancho San Andrés Castro Adobe; Santa Cruz Archaeological Society: Soquel, CA, USA, 2017. 